\title{
Constraining climatic controls on hillslope dynamics using a coupled model for the transport of soil and tracers: Application to loess-mantled hillslopes, South Island, New Zealand
}

\author{
Joshua J. Roering \\ Department of Geological Sciences, University of Oregon, Eugene, Oregon, USA \\ Peter Almond and Philip Tonkin \\ Soil and Physical Sciences Group, Soil, Plant, and Ecological Sciences Division, Lincoln University, Canterbury, New \\ Zealand
}

James McKean

Rocky Mountain Research Station, Forest Service, United States Department of Agriculture, Boise, Idaho, USA

Received 28 February 2003; revised 9 December 2003; accepted 19 December 2003; published 24 February 2004.

[1] Landscapes reflect a legacy of tectonic and climatic forcing as modulated by surface processes. Because the morphologic characteristics of landscapes often do not allow us to uniquely define the relative roles of tectonic deformation and climate, additional constraints are required to interpret and predict landscape dynamics. Here we describe a coupled model for the transport of soil and tracer particles at the hillslope scale. To illustrate the utility of this methodology, we modeled the evolution of two synthetic hillslopes with identical initial and boundary conditions but different histories of climateinduced changes in the efficiency of soil transport. While one hillslope experienced an initial phase of rapid transport followed by a period of retarded transport, the other hillslope experienced the opposite sequence. Both model hillslopes contain a subsurface layer of tracer particles that becomes exhumed and incorporated into the soil due to transport and mixing processes. Whereas the morphology of the two model hillslopes cannot be easily distinguished at the simulation conclusion, the spatial distribution of tracer particles along the slope is distinctive for the two cases. We applied the coupled model to our study site along the Charwell River, South Island, New Zealand, where tephra deposits within loess-dominated soils have been exhumed and incorporated into an upper layer of bioturbated and mobile soil. We reconstructed the late Pleistocene hillslope geometry using soil stratigraphic data gathered along the study transect. Because bioturbation appears to be the predominant transport mechanism, the efficiency of soil transport likely varies with time, reflecting the influence of climate-related changes in the dominant floral or faunal community. The modeled evolution of hillslope form and tephra concentration along the study transect is consistent with observations obtained from topographic surveys and laboratory analysis of tephra concentrations in continuous-core soil samples. Low transport rates are apparently associated with grass/shrub-dominated slopes during the late Pleistocene, whereas forest colonization during the Holocene increased flux rates, transforming flat, locally incised slopes into broadly convex ones. Our results attest to the utility of coupled models for tasks such as deciphering landscape history and predicting the downslope flux of soil organic carbon. INDEX TERMS: 1815 Hydrology: Erosion and sedimentation; 1625 Global Change: Geomorphology and weathering $(1824,1886)$; KEYWORDS: landscape evolution, soil transport, tracers, hillslope erosion, bioturbation, numerical model

Citation: Roering, J. J., P. Almond, P. Tonkin, and J. McKean (2004), Constraining climatic controls on hillslope dynamics using a coupled model for the transport of soil and tracers: Application to loess-mantled hillslopes, South Island, New Zealand, J. Geophys. Res., 109, F01010, doi:10.1029/2003JF000034.

\section{Introduction}

[2] Recent efforts to explore linkages between landscapes, climate, and tectonics have relied heavily on the principle that characteristic metrics of landscape form result 
from a unique suite of surface processes [Heimsath et al., 2001; Howard, 1997; Kirkby, 1971; Roering et al., 2001a; Seidl and Dietrich, 1992; Stock and Dietrich, 1999]. For example, convex hillslopes are generally thought to result from a slope dependency on soil transport rates, whereas the tendency for channel gradients to decrease with increasing drainage area in bedrock rivers may result because incision is proportional to stream power (as calculated with drainage area and channel gradient). This so-called process/form connection allows for the testing and calibration of sediment transport and erosion models, which can then be applied to map the spatial distribution of erosion and uplift rates [Kirby and Whipple, 2001; Montgomery, 2001; Snyder et al., 2000]. As demonstrated by Dunne [1991], however, process/form linkages may not necessarily be unique as a suite of different erosional processes with different intensities may generate a similar landform. This emphasizes the need to better constrain and formalize the mechanics of surface processes.

[3] To test surface process models and develop tectonic and topographic linkages, many studies have utilized assumptions such that erosion rates are balanced by uplift rates over some appropriate spatial and temporal scale [Burbank et al., 1996; Hack, 1960; Heimsath et al., 1997; Riebe et al., 2001; Roering et al., 1999; Willett and Brandon, 2002]. Although this methodology is conceptually appealing and typically simplifies computations, the steady state assumption can be difficult to test because it requires documenting the spatial distribution of erosion rates across a range of temporal and spatial scales [Whipple, 2001; Willett and Brandon, 2002]. This limits our ability to test geomorphic transport models and quantify linkages between topography, surface processes, and tectonic forcing.

[4] The morphology of landscapes is governed not only by the current configuration of surface processes but also by landscape history [Howard, 1997]. Fluctuations in the efficacy of surface processes associated with climate change may be significant, thus clouding our ability to uniquely relate rock uplift rates to landscape form [Fernandes and Dietrich, 1997; Kirkby, 1989; Small and Anderson, 1998]. Apart from topographic data and erosion rate estimates, little additional information has been used to constrain surface process models and interpret landscape dynamics. As suggested by Furbish [2003], we might better utilize additional data sets to test and calibrate the growing suite of landscape evolution models used to interpret spatial and temporal patterns of tectonic forcing. Here we embrace this methodology and describe our efforts to constrain climatic controls on soil transport using topographic data coupled with depth profiles of tephra concentration.

[5] The downslope transport of soil in the absence of overland flow has been attributed to numerous mechanisms, including tree turnover, wet/dry or freeze/thaw cycles, rheologic creep, and faunal burrowing [Finlayson, 1985]. In forested landscapes the accumulation of coarse clasts in the upper layers of soils [Small et al., 1990] and the preponderance of pit/mound topography [Denny and Goodlett, 1957] suggests that tree turnover may be a dominant mechanism of soil disturbance and transport. Root growth and tree turnover events may be frequent enough to retard or even stymie the development of well-stratified soil horizons [Schaetzl et al., 1990]. Soils within the rooting zone experience periodic and randomly distributed detachment and transport, increasing soil homogeneity [Schaetzl, 1986]. Alternatively, in grass-covered landscapes, soils often exhibit distinct horizonation due to suppressed rates of disturbance [Birkeland, 1999]. In addition to biogenic influences, the rate and style of transport varies with soil properties [Mitchell, 1993], although the relative importance of these factors is poorly known.

[6] Given that climate change during the Quaternary occurs over thousand-year timescales, it is probable that many hilly, soil-mantled landscapes have alternated between grass, shrub, and forest-dominated regimes [Blinnikov et al., 2002; Worona and Whitlock, 1995]. The relative importance of soil transport mechanisms may have varied accordingly. Similarly, Anderson [2002] suggests that frost-driven transport on high alpine surfaces likely waxes and wanes in response to climate change. A major difficulty in interpreting the development of soil-mantled hillslopes is determining to what extent the current morphology has been influenced by previous periods under a different climate regime. Slope-dependent transport models used to simulate hillslope processes tend to diffuse landscapes and obliterate distinctive features that might otherwise be diagnostic such that a landform with a particular morphology may arise from numerous climatic scenarios.

[7] Here we describe a methodology for improving the quantitative interpretation of hillslope dynamics. Along soil-mantled hillslopes on the South Island of New Zealand, previous work has documented evidence for disturbancedriven soil mixing and transport due to biogenic activity, specifically, tree turnover and root growth [Roering et al., 2002]. This interpretation is based on the distribution of volcanic glass grains from a tephra deposit buried by loess during the Last Glacial Maximum (LGM). Forest colonization during the Holocene led to invigorated soil transport and erosion of the landscape surface. As a result, the tephra deposit was exhumed and became incorporated into the upper, mobile layer of soil. Along the transect the concentrated tephra spike became highly diffuse once exhumed to a particular depth, consistent with the rooting depth of trees that colonized the area. In this contribution we develop a numerical model to explore the hypothesis that sediment transport rates increased in response to the conversion of grasslands to forest. Our simulations demonstrate that not only hillslope form but also the concentration of tracer particles can be used to constrain soil transport mechanisms and interpret hillslope dynamics. Our results from theoretical and loess-mantled hillslopes in our New Zealand study site allow us to quantify fluctuations in the development of hilly terrain as well as more explicitly account for climate controls on the efficacy of erosional processes.

\section{Coupled Model of Soil and Tracer Transport}

[8] There are several advantages to using coupled models for interpreting and predicting landscape dynamics. Typically, efforts to evaluate the efficacy of landscape evolution simulations involve comparing numerically generated topography with actual topographic data. Furbish [2003] suggests that fundamental process mechanics may not be 


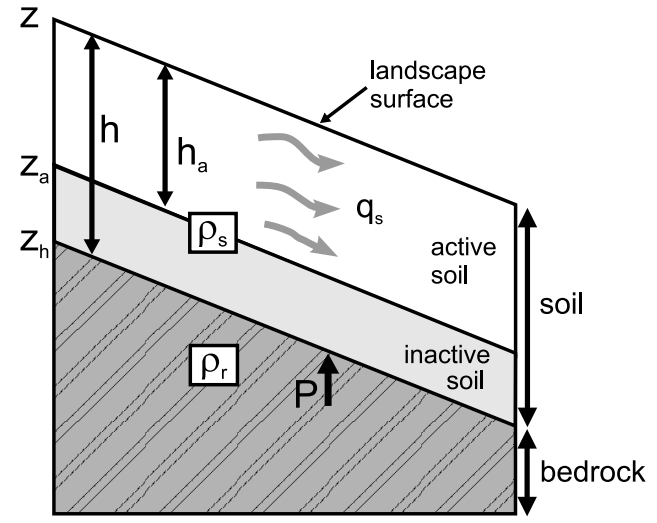

Figure 1. Schematic section along a soil-mantled hillslope. Disturbance processes (such as tree throw or freeze/ thaw activity) focus sediment transport $\left(q_{s}\right)$ in the upper layer of soil $\left(h_{a}\right)$, while an inactive layer may persist below. Soil production from the transformation of bedrock is represented by $P$.

apparent without additional constraints in the form of dependent variables that describe some property of the landscape system. These data sets may include maps of the spatial distribution of organic carbon, soil depth, radiogenic tracers, or lithologic markers. The additional information provided by these sources may allow us to (1) test and reject specific geomorphic transport models, thus narrowing the list of valid models, (2) calibrate geomorphic transport models, (3) better constrain initial conditions, and (4) identify temporal variations in the efficacy of particular surface processes.

\subsection{Conceptual Model}

[9] In soil-mantled landscapes, agents that disturb and transport material may not penetrate the entire soil depth. In this contribution we draw a distinction between soil that experiences active transport due to bioturbation, freeze/ thaw activity, or other processes and soil that is insolated from such disturbances [e.g., Cox, 1998; Johnson, 1990]. Given local aggradation (such as in topographic convergent areas or colluvial hollows), the total soil depth $(h)$ may exceed the active depth $\left(h_{a}\right)$, generating a layer of geomorphically inactive material having a thickness equal to $h-h_{a}$ (Figure 1). Conversely, where soil is sufficiently thin the penetration depth of transport processes (such as freeze/thaw) may be limited by the amount of available soil. Although discrete bounds separate layers in this conceptual model, such interfaces are likely to be somewhat diffuse in real landscapes.

\subsection{Soil Transport}

[10] For over 100 years the convex shape of soil-mantled hillslopes has been attributed to slope-dependent sediment transport processes driven by disturbances such as wet/dry and freeze/thaw cycles, biogenic activity, and raindrop impacts [Davis, 1892; Gilbert, 1909]. Culling [1960] modeled volumetric flux $\left(q_{s}\right)\left(\mathrm{m}^{2} \mathrm{yr}^{-1}\right)$ as proportional to hillslope gradient, and Roering et al. [1999] followed the conceptual framework of Howard [1994] and Anderson [1994] and used physical arguments to propose that volumetric soil flux varies nonlinearly with gradient according to

$$
q_{s}=-K \frac{\partial z / \partial x}{1-\left(\frac{\partial z / \partial x}{S_{c}}\right)^{2}},
$$

where $K$ is a transport coefficient $\left(\mathrm{m}^{2} \mathrm{yr}^{-1}\right), S_{c}$ is a critical gradient, $z$ is elevation $(\mathrm{m})$, and $x$ is horizontal distance $(\mathrm{m})$. Equation (1) is consistent with recent field studies, which indicate that soil flux may increase nonlinearly on steep slopes [Gabet, 2000; Roering et al., 1999], and with experimental data [Roering et al., 2001b]. Braun et al. [2001] and Furbish and Fagherazzi [2001] suggest that soil flux may depend on soil thickness such that flux is proportional to the product of gradient and soil thickness. On the basis of observations from their New Zealand study site, Roering et al. [2002] suggest that the depth of mobile regolith in forested landscapes may be controlled by the characteristic scale of bioturbation. Similarly, Anderson [2002] argues that the penetration of freeze/thaw action on high alpine surfaces may limit the depth to which regolith can be recruited for transport and mixing. Given a sufficiently thick soil mantle, the depth of active soil may be effectively constant under a particular floral assemblage or climatic regime. Equation (1) represents transport mechanisms for which flux does not explicitly vary with soil thickness; instead, flux rates depend on the frequency, magnitude, and spatial scale of disturbances. As elaborated by Anderson [2002], however, transport rates may be limited when the potential depth of transport agents exceeds the depth of available soil. In such cases the transport coefficient $(K)$ decreases roughly in proportion to the difference between the potential transport depth and the actual soil depth and approaches zero when bedrock emerges at the surface.

\subsection{Mass Conservation and Soil Production}

[11] In order to calculate the evolution of topography according to soil transport and production processes, we use a one-dimensional equation for mass conservation of soil on a hillslope:

$$
\frac{\partial h}{\partial t}=-\frac{\partial q_{s}}{\partial x}+\frac{\rho_{r}}{\rho_{s}} P,
$$

where $\rho_{s}$ and $\rho_{r}$ are the average bulk density of soil and rock $\left(\mathrm{kg} \mathrm{m}^{-3}\right)$, respectively, $t$ is time (years), and $P$ is the rate of soil production from transformation of bedrock $\left(\mathrm{m} \mathrm{yr}^{-1}\right)$. Several models describing how $P$ varies with soil depth have been proposed and tested using cosmogenic radionuclides, topographic analyses, and forward modeling [Dietrich et al., 1995; Heimsath et al., 1997; Small et al., 1999]. Heimsath et al. [2000] and Heimsath et al. [1997] demonstrated that $P$ decreases exponentially with depth such that maximum rates of conversion occur on bare bedrock surfaces. Alternatively, several mathematical functions have been proposed to account for the possibility that maximum rates occur at a finite soil depth [Anderson, 2002; Carson and Kirkby, 1972; Gilbert, 1877; Small et al., 1999]. When soils are sufficiently thick, $P$ approaches zero. 


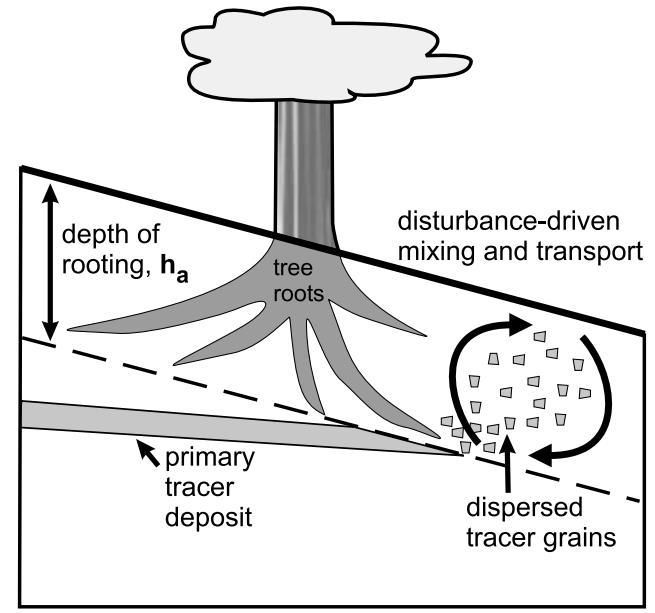

Figure 2. Schematic of tracer exhumation and subsequent dispersal in the actively disturbed upper soil layer. The depth of disturbance is responsible for the mixing of tracer particles and is controlled by stochastic biogenic activity (in this case, root growth and tree turnover). Mixing may be rapid enough that the tracer concentration in the upper soil layer is relatively uniform. Alternative processes, such as faunal burrowing, may produce a similar result.

Equations (1) and (2) can be combined, enabling us to relate the rate of soil depth change to topographic derivatives, model parameters, and initial and boundary conditions. The elevation of the land surface can be calculated given soil depth and the elevation of the soil/bedrock interface.

\subsection{Tracer Transport}

[12] A conservation equation is required to calculate the spatial and temporal variation of a particular tracer. In this contribution the coupling between soil and tracers is based on the assumption that once an ensemble of tracer particles is introduced into the mobile soil layer $\left(h_{a}\right)$, stochastic disturbance processes cause the tracer to be dispersed and well mixed such that the concentration is relatively uniform (Figure 2). Henceforth the tracers are transported indiscriminately amongst mobile soil particles. In effect, the same processes responsible for driving soil transport also serve to mix and homogenize soils. The tracer may be introduced to the active soil layer by any number of pathways (such as infiltration or air fall), although in this formulation we only consider the addition of tracer particles through exhumation (Figure 2). As such, tracer particles reside at depth, below the zone of mobile regolith, and erosion causes the tracers to be exhumed and incorporated into the mobile layer. The following one-dimensional conservation equation describes how the average tracer concentration in the upper soil $(\phi)$ $\left(\mathrm{kg} \mathrm{m}^{-3}\right)$ evolves in time and space:

$$
\frac{\partial}{\partial t}\left(h_{a} \phi\right)=-\frac{\partial}{\partial x}\left(h_{a} \overline{v \phi}\right)-\phi_{b}(z) \frac{\partial z_{a}}{\partial t},
$$

where $\bar{v}$ is the average horizontal velocity of the active soil layer, $h_{a} \overline{v \phi}$ is the tracer mass flux rate $\left(\mathrm{kg} \mathrm{m}^{-1} \mathrm{yr}^{-1}\right), z_{a}$ is the elevation of the base of the active soil layer (see Figure 1), and the function $\phi_{b}(z)$ describes the tracer concentration profile below the active soil layer. In this formulation we assume that average tephra concentration and average soil velocity are not correlated such that $\overline{v \phi} \cong \bar{v} \cdot \bar{\phi}$. Combining the relation $q_{s}=h_{a} \bar{v}$ and equation (1), average soil velocity can be calculated by solving for $\bar{v}$.

[13] The first term on the right-hand side of equation (3) quantifies concentration changes as a result of differences in the amount of tracer entering and exiting a given element of soil along the hillslope. The final term describes the addition of tracers into the upper soil layer by exhumation. Tracer concentration varies with depth below the active transport layer, and the rate at which tracers are incorporated into the soil depends on the erosion rate. Although we formulated the model for conservative tracers, equation (3) can be adapted to account for tracers with known rates of decay or production.

\subsection{Model Implementation and Coupling}

[14] Coupling the evolution of hillslope topography and the variation of tracer concentration is achieved via the right-hand side of equation (3) as concentration variations depend on hillslope geometry and soil transport rates. To realize the coupling, we constructed a numerical model to dynamically solve equations (2) and (3) using a onedimensional, adaptive-time-step numerical algorithm [Press et al., 1992]. To quantify the incorporation of tracers from the substrate, we included an integration subroutine whereby incremental exhumation results in the addition of tracers to the upper soil layer (Figure 3). Concentration changes occur due to exhumation as tracer particles move upward into the mobile layer. Sediment accumulation at the surface may conversely cause the tracer particles to be buried more deeply. During each time step the mass of added

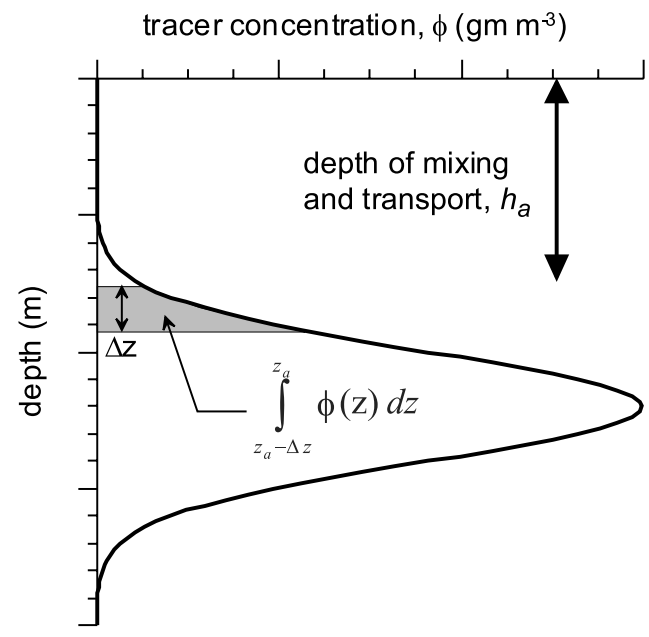

Figure 3. Schematic of tracer concentration below the active soil layer. With lowering of the surface, tracer particles are exhumed and incorporated into the active soil layer $\left(h_{a}\right) . \Delta z$ illustrates the incremental depth of erosion (and thus exhumation) during a given time step of our coupled soil/tracer model. The shaded area represents the integrated mass of tephra added during the time step. Erosion causes the tracer layer to become further exhumed such that more particles are progressively added to the active soil layer, whereas deposition acts to further bury the deposits. 
particles (measured in mass per unit area) is calculated according to

$$
\int_{z_{a}-\Delta z}^{z_{a}} \phi_{b}(z) d z
$$

where $\Delta z$ is the incremental amount of surface lowering and $z_{a}$ is the elevation of the base of the active soil layer $\left(h_{a}\right)$ (Figure 3). Because tracer particles are distributed through the thickness of active soil, concentrations in the mobile layer will tend to be significantly lower than peak concentrations in the substrate.

\subsection{Simulating Climate-Driven Variations in Transport Efficiency}

[15] To explore the utility of coupled soil/tracer simulations for interpreting landscape dynamics, we compared one-dimensional simulations of two synthetic hillslopes that evolved with identical initial and boundary conditions but with different climatic histories. Climate changes may result in the transformation of flora and faunal assemblages such that rates of soil disturbance and transport vary contemporaneously. Here we account for different climatic regimes by varying the value of $K$ that represents disturbance-driven soil transport.

\subsubsection{Initial and Boundary Conditions}

[16] Both hillslopes have a horizontal dimension of $60 \mathrm{~m}$, are initially flat (i.e., undissected surfaces), and experience base-level lowering of $0.1 \mathrm{~mm} \mathrm{yr}^{-1}$ at $x=-30$ and $x=30 \mathrm{~m}$. The hillslopes are transport limited such that soil is always available for transport and soil production $(P)$ is effectively zero. The variation of $K$ is shown in Figure 4e. For simulation 1 ( $\operatorname{sim} 1), K$ begins high $\left(0.02 \mathrm{~m}^{2} \mathrm{yr}^{-1}\right)$, decreases by a factor of 4 after $15 \mathrm{kyr}$, and then increases by a factor of 2 after another $15 \mathrm{kyr}$, whereas for $\operatorname{sim} 2, K$ begins low $\left(0.005 \mathrm{~m}^{2} \mathrm{yr}^{-1}\right)$, increases after $15 \mathrm{kyr}$, and decreases by a factor of 1.5 after an additional $15 \mathrm{kyr}$. In real landscapes, such fluctuations may arise from changes between grass-dominated, shrub-dominated, and forestdominated ecosystems. For this exercise we chose arbitrary values of $K$ within the range expressed by studies in a variety of climatic settings [Hanks, 2000]. For simplicity, we set the value of $h_{a}$ equal to $0.5 \mathrm{~m}$, although in real landscapes it likely varies in concert with $K$. The value of $S_{c}$ (equation (1)) was set to 1.25 .

[17] In both cases a layer of tracer material is buried at a depth of $1 \mathrm{~m}$. The depth distribution of the tracer (which consists of a distinctive material such as volcanic deposits or buried carbon) is represented with a normal distribution (e.g., Figure 3). The peak concentration occurs at $1.0 \mathrm{~m}$ depth and the standard deviation of the distribution is $0.1 \mathrm{~m}$ such that $95 \%$ of the tracer mass is found between 0.8 and $1.2 \mathrm{~m}$ depth.

\subsubsection{Synthetic Hillslope Simulations}

[18] Using our coupled numerical model, we simultaneously solved equations (2) and (3) to determine the temporal distribution of hillslope elevation and tracer concentration given the specified parameters. Because the hillslopes are symmetrical about the emerging hill crest (Figures $4 \mathrm{a}$ and $4 \mathrm{~b}$ ), we show results for half of the modeled hillslopes (from crest $(x=0)$ to channel $(x=30 \mathrm{~m})$ ). The hillslope develops convexity as the effect of base-level lowering propagates upslope. During the first $15 \mathrm{kyr}$ the convexity in sim 1 is much broader than that developed in sim2. During the second phase, this contrast is reversed as the hillslopes trade high and low $K$ values (Figure 4e). Finally, the modeled profiles appear to approach a similar shape near the simulation conclusion ( $\sim 0-45 \mathrm{kyr})$, as both models erode with the same value of $K$.

[19] These morphologic trends are reflected in Figure 4e, which illustrates how the average difference in curvature (ADC) for the two hillslopes varies with time. This quantity allows us to track the morphologic similarity of the two hillslopes and is calculated according to

$$
\mathrm{ADC}=\frac{\sum_{i=1}^{n}\left|\left(\partial^{2} z / \partial x^{2}\right)_{1 i}-\left(\partial^{2} z / \partial x^{2}\right)_{2 i}\right|}{n},
$$

where $n$ is the number of nodes in the model hillslope and the subscripts 1 and 2 refer to the two simulations. The bars in Figure 4e show the standard deviation of ADC. At time $t=0$, both hillslopes are flat and thus have similar curvature $(\mathrm{ADC}=0)$. As base-level lowering proceeds, different convexities emerge, and ADC approaches a large value. Following the climate-related shift in $K$ values at $15 \mathrm{kyr}$, the ADC dips temporally and then approaches a high value. During the two periods of high morphologic divergence (10-15 and 25-30 kyr), curvature values on the two hillslopes are highly disparate, as shown by the mean and standard deviation in Figure 4e. Finally, between 30 and $45 \mathrm{kyr}$ the hillslopes attain an increasingly similar morphology as both are eroding with $K=0.01 \mathrm{~m}^{2} \mathrm{yr}^{-1}$. After $40 \mathrm{kyr}$ the value of ADC is increasingly low such that field-based curvature measurements would be unlikely to distinguish between the two slopes. This exercise demonstrates the nonuniqueness (equifinality) of morphologic criteria used to describe hillslope adjustment.

[20] Concurrent with erosion of the hillslope, the concentration of tracers in the upper soil evolves, attaining a characteristic pattern for the two simulations. After $\sim 12 \mathrm{kyr}$, base-level lowering erosion is greatest near the channel margins such that tracer particles first emerge at these locations (Figures $4 \mathrm{c}$ and $4 \mathrm{~d}$ ). Progressive incision results in the upslope translation of a wave of elevated tracer concentrations. Through the simulation, these concentration waves attain a maximum value at the hillslope crests due to the superposition of waves from either sideslope. It is noteworthy that the dynamics of these waves differ markedly for the two cases. For sim1 the peak concentration remains relatively constant while progressing upslope between 15 and $33 \mathrm{kyr}$, whereas in the case of simulation $\operatorname{sim} 2$ the peak concentration increases monotonically during the period between 15 and $27 \mathrm{kyr}$. In addition, the waveforms are distinctive: The sim1 waves are steeper on the upslope side and exhibit a well-defined peak, whereas sim2 waves are more diffuse as concentrations gradually decrease toward the channel margin. These differences result from the contrasting pattern of hillslope adjustment for the two simulations, which controls the timing and pattern of tracer exhumation into the active soil layer.

[21] Near the end of the simulations (after $42 \mathrm{kyr}$ ), the distribution of tracer particles is significantly different. For 


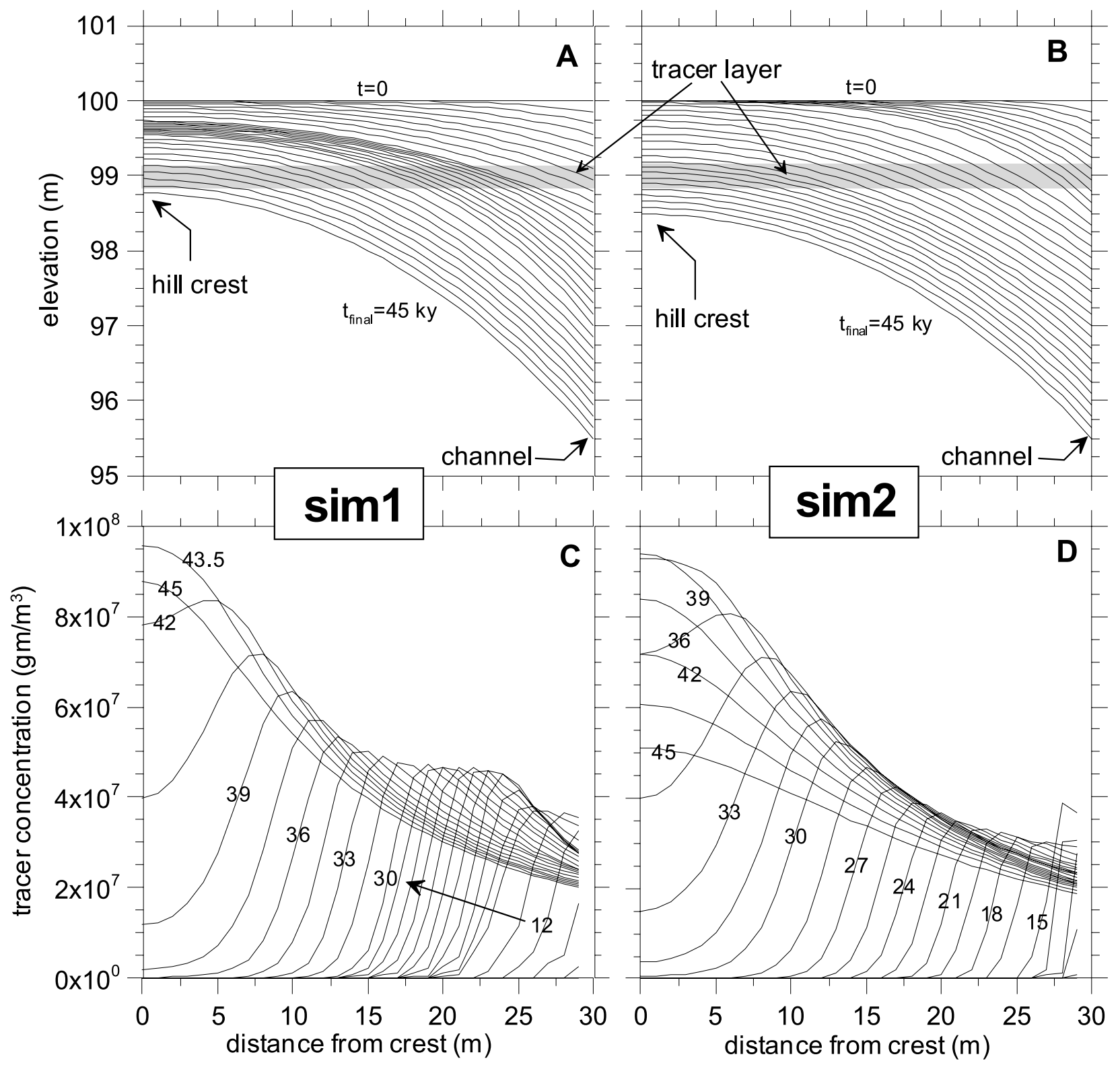

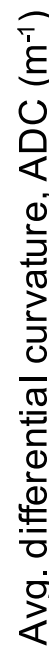

表

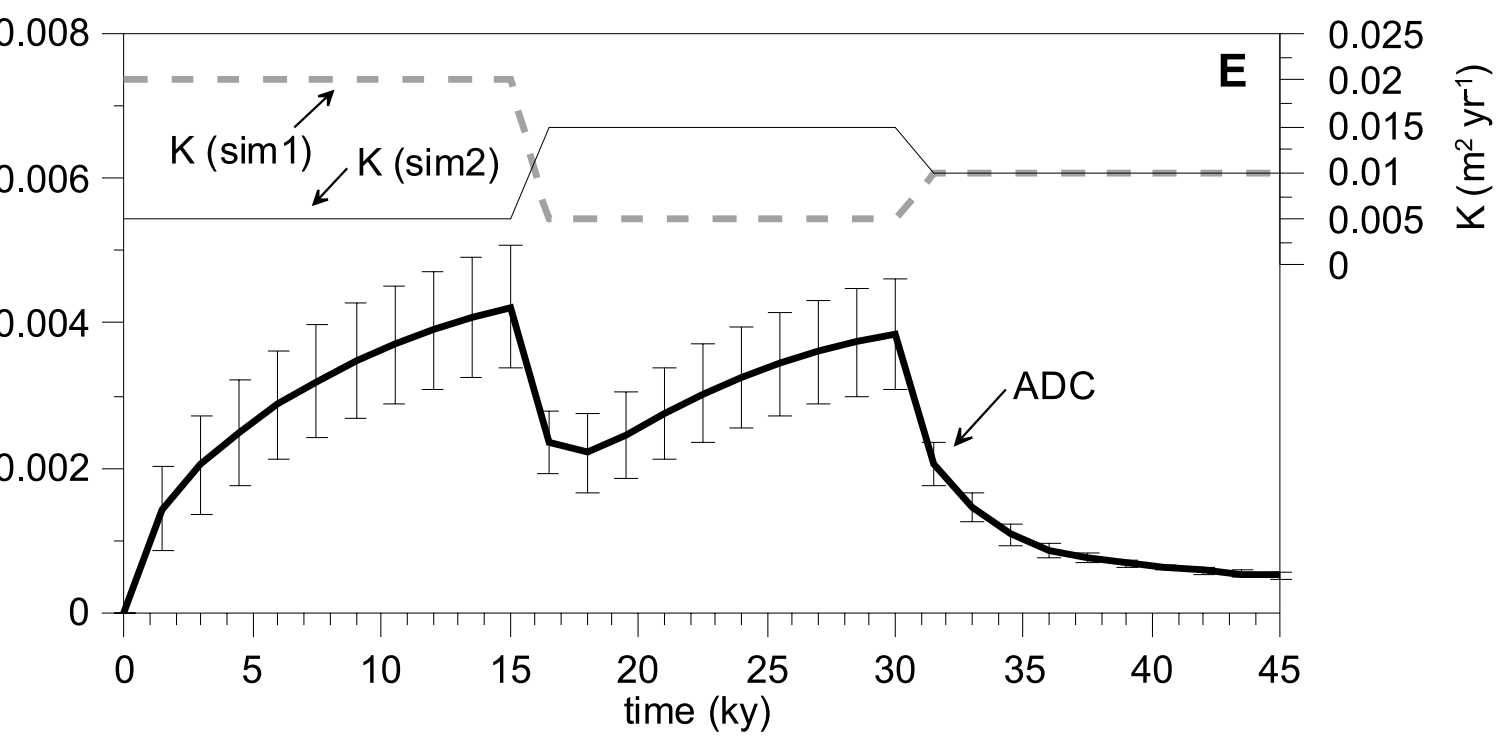

Figure 4. 
both cases, no tracer particles are present below the active soil layer as the primary tracer source has been exhausted. Nonetheless, the distribution of tracer particles in the active layer shows different patterns and may be used to differentiate the two cases. Following $42 \mathrm{kyr}$, concentrations in sim 1 are elevated near the crest and decrease significantly downslope, whereas in sim2, concentrations are lower by a factor of two and decrease gradually downslope. The temporal variation of tracer concentration at three locations along the modeled hillslopes is shown in Figure 5. Tracer concentrations near the channel margin exhibit similar variations through time for the two cases (Figure 5a), whereas midslope and near the crest (Figures $5 \mathrm{~b}$ and $5 \mathrm{c}$ ), the temporal pattern of concentration differs significantly through the simulation. This result suggests that field investigations of tracer concentration should be focused in upslope areas if the aim is to distinguish between hillslope responses to different climate scenarios.

[22] The applicability of this methodology depends on the availability of site parameters such as the initial distribution of tracer material and evidence for the relative importance of different soil transport processes through time. These simulations demonstrate the utility of additional constraints when analyzing the dynamics of geomorphic systems. Whereas morphologic data alone (e.g., hillslope curvature) cannot readily differentiate between the two hillslope simulations, tracer concentrations reveal their divergent legacies. In section 6 we describe an application of the coupled model to hillslopes in New Zealand.

\section{Study Site: Charwell River, South Island, New Zealand}

[23] Along the Charwell River on the South Island of New Zealand, well-documented fluvial terrace remnants record episodes of aggradation and channel incision through the late Quaternary [Bull, 1991]. Bounding the Seaward Kaikoura Range to the north, the Hope fault separates the steep, highly dissected portion of the humid Charwell drainage basin $\left(40 \mathrm{~km}^{2}\right)$ from low-relief terrain, where aggradational terraces are dominant (Figure 6). The basin is underlain by massive to bedded graywacke belonging to the Torlesse supergroup [Campbell and Coombs, 1966]. High rates of right-lateral slip $\left(20-35 \mathrm{~mm} \mathrm{yr}^{-1}\right)$ and

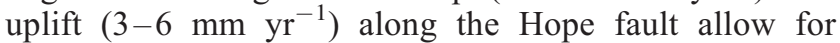
the accumulation and preservation of alluvial deposits south of the range [Bull, 1991]. As a result, terrace remnants
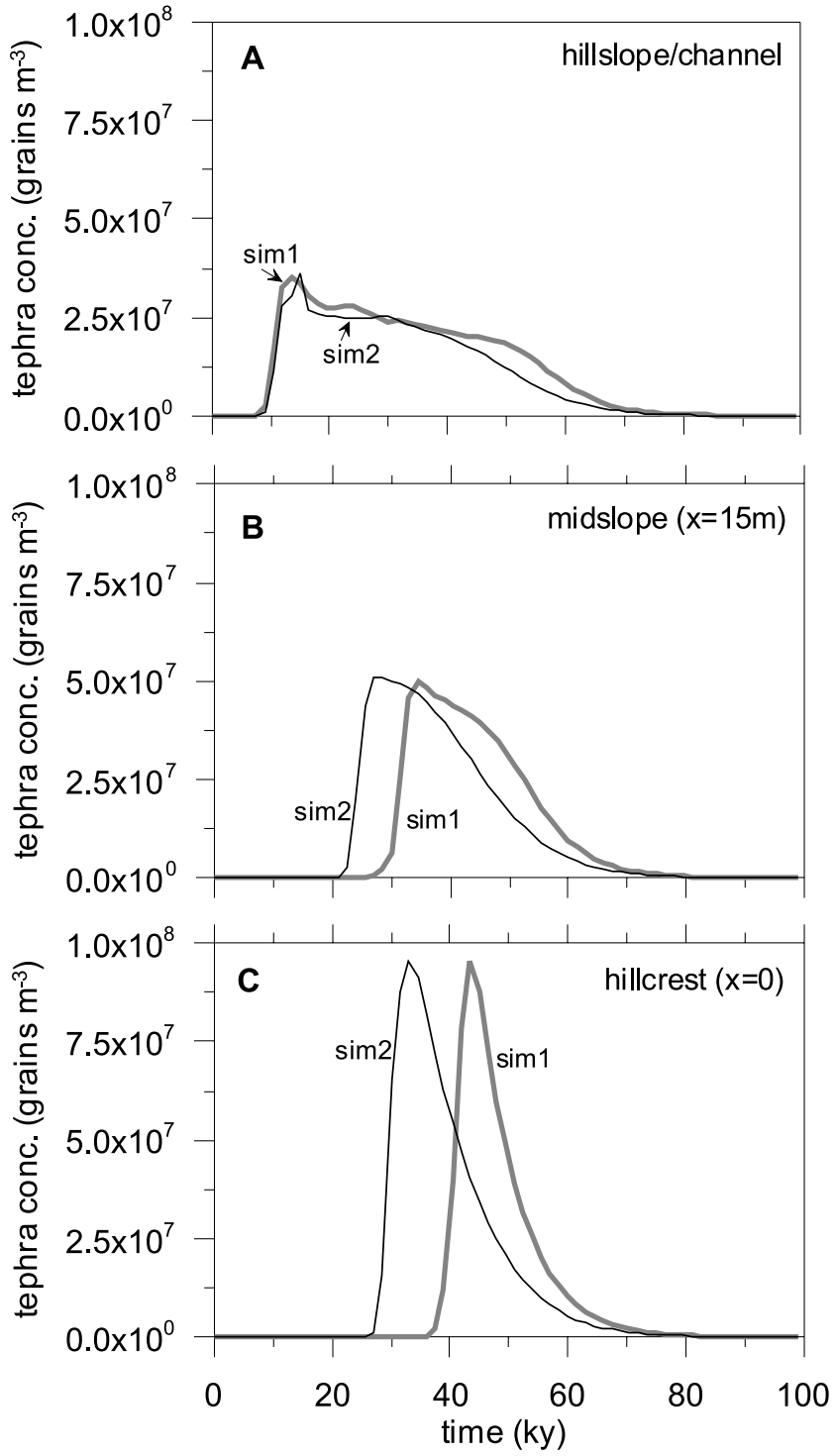

Figure 5. Time series for the tephra concentration at three different points along the modeled hillslopes summarized in Figure 4. Near the channel margin (Figure 5a), the concentration values are similar for the two cases ( $\operatorname{sim} 1$ and sim2) as most tracer particles are generated from upslope. From the midslope (Figure 5b) to hillcrest (Figure 5c) locations $(x=15 \mathrm{~m}$ and $x=0 \mathrm{~m}$, respectively), concentrations diverge significantly in time.

Figure 4. Summary of coupled soil/tracer transport simulations for two synthetic hillslopes with similar initial conditions (flat surface, $t=0)$ and channel lowering rates $\left(0.1 \mathrm{~mm} \mathrm{yr}^{-1}\right)$. Half the symmetrical slopes (from hill crest to channel margin) are shown here for brevity. The value of $K$ varies with time for each case. (a) Successive profiles of hillslope elevation for simulation $1(\operatorname{sim} 1)$, beginning with $t=0$ and finishing at $t=45 \mathrm{ka}$. The profile interval is $1.5 \mathrm{kyr}$. The buried layer of tracer particles is shown by a horizontal gray bar at $z=99 \mathrm{~m}$. (b) same as Figure 4a, but for sim2. (c) Successive profiles of tracer concentration in the upper, mobile soil column $\left(h_{a}=0.45 \mathrm{~m}\right)$ for $\operatorname{sim} 1$. The time interval between profiles is $1.5 \mathrm{kyr}$. The arrow from 12 to 30 reflects the progression of profiles with $1.5 \mathrm{kyr}$ intervals. (d) same as Figure 4c, but for sim2. (e) Time series of $K$ values for the two simulations, sim1 (shown by the thick, dashed gray line) and sim2 (shown by the thin black line) and values of average differential curvature (ADC), which quantifies the average morphologic difference of the two cases (see text). As shown in Figures $4 \mathrm{a}-4 \mathrm{~d}$, tracer concentration values experience a wave-like upslope propagation in response to land surface erosion (and exhumation of the tracer layer at $z=99 \mathrm{~m})$. Near the conclusion of the simulations $(t=$ $42-45 \mathrm{ka})$, the value of ADC is small such that the morphology of the two slopes is indistinguishable, yet the tephra distributions are distinctive. Error bars for ADC values indicate one standard deviation $(1 \sigma)$. 


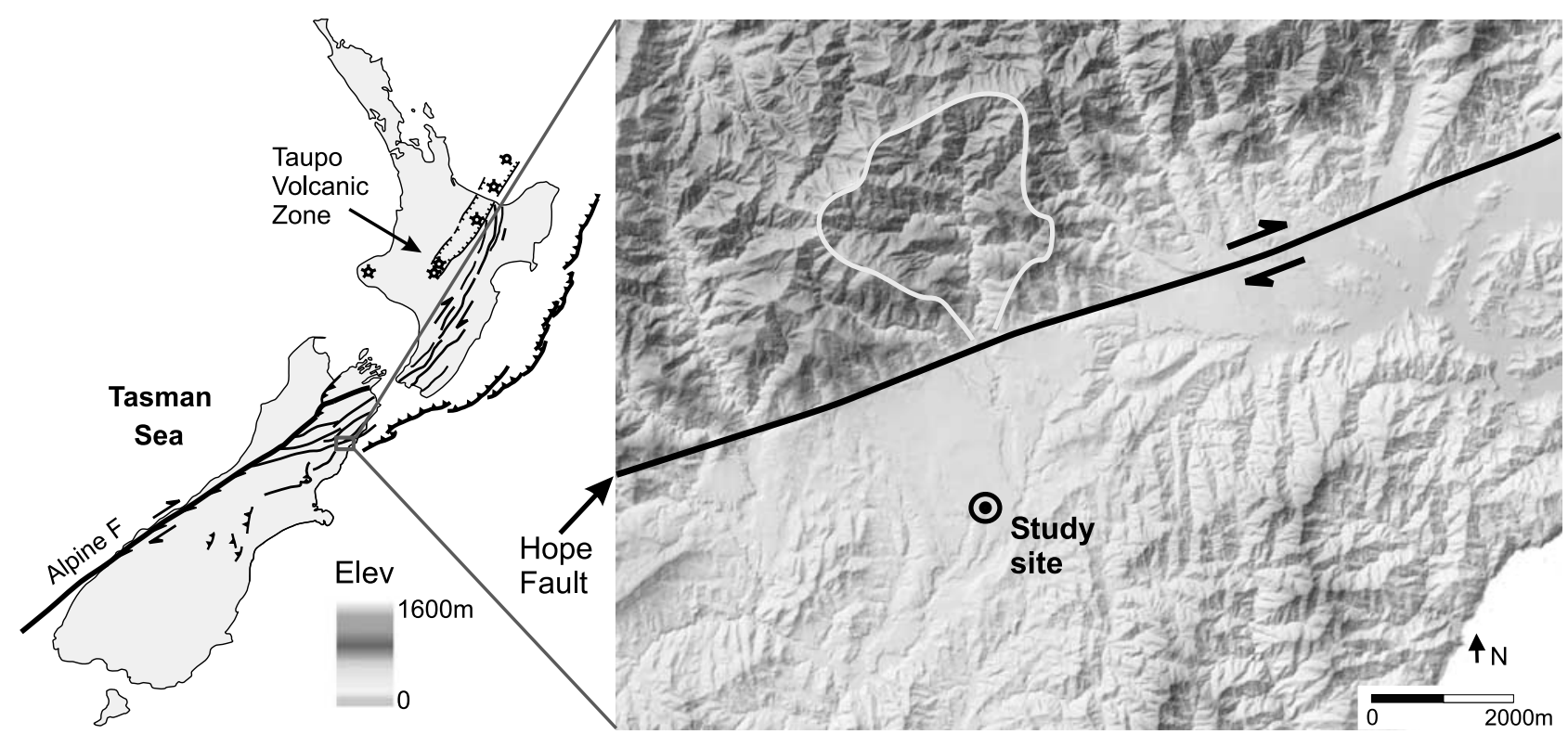

Figure 6. Location map for our Charwell River, South Island, New Zealand, study site. The unglaciated Charwell basin (shown in outline), which drains across the Hope fault (shown trending east-west), has generated a sequence of late Quaternary aggradational and strath terraces on the south side of the fault. The Hope fault experiences $20-35 \mathrm{~mm} \mathrm{yr}^{-1}$ of right-lateral slip and 3-6 mm yr ${ }^{-1}$ of uplift. See Bull [1991] for further description. See color version of this figure in the HTML.

are progressively older southwest of the current channel location.

[24] Figure 7 illustrates the varying degrees of dissection and relief development found among the terrace remnants. In the foreground, fluvial gravel deposits associated with a period of late Quaternary aggradation (termed Stone Jug by Bull [1991]) are distinguished by well-defined terrace treads and risers that have experienced relatively little erosional alteration. In the middle ground, terrace remnants (termed Dillondale by Bull [1991]) have been associated with the

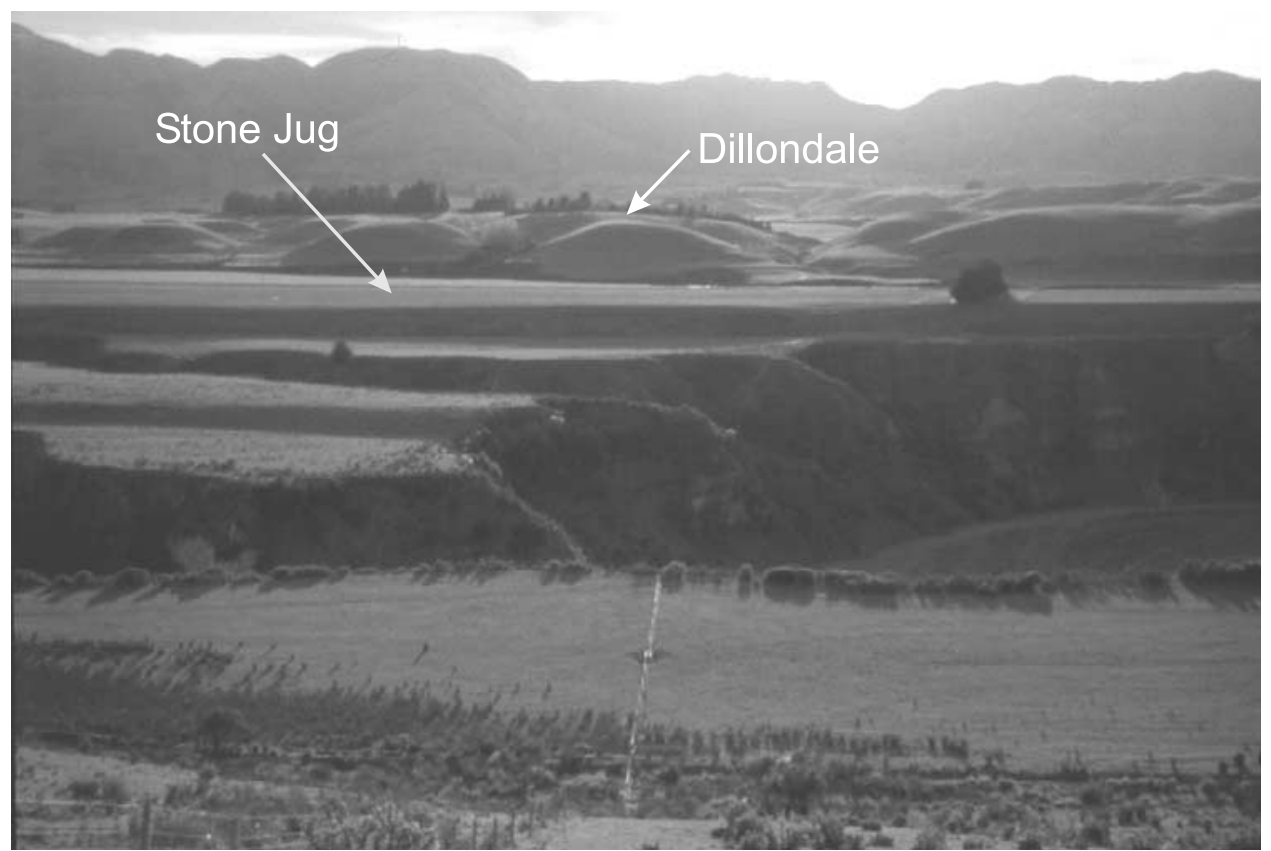

Figure 7. Photo of Charwell River terraces. Stone Jug surfaces in the foreground are undissected and are associated with the Last Glacial Maximum. Dillondale surfaces in the middle ground (denoted by an arrow) are associated with the penultimate glaciation and have experienced significant incision and hillslope degradation (see Figure 8 for characteristic profile). The older Quail Downs surfaces are barely visible between the Dillondale remnants and the ridgeline on the horizon. See color version of this figure in the HTML. 


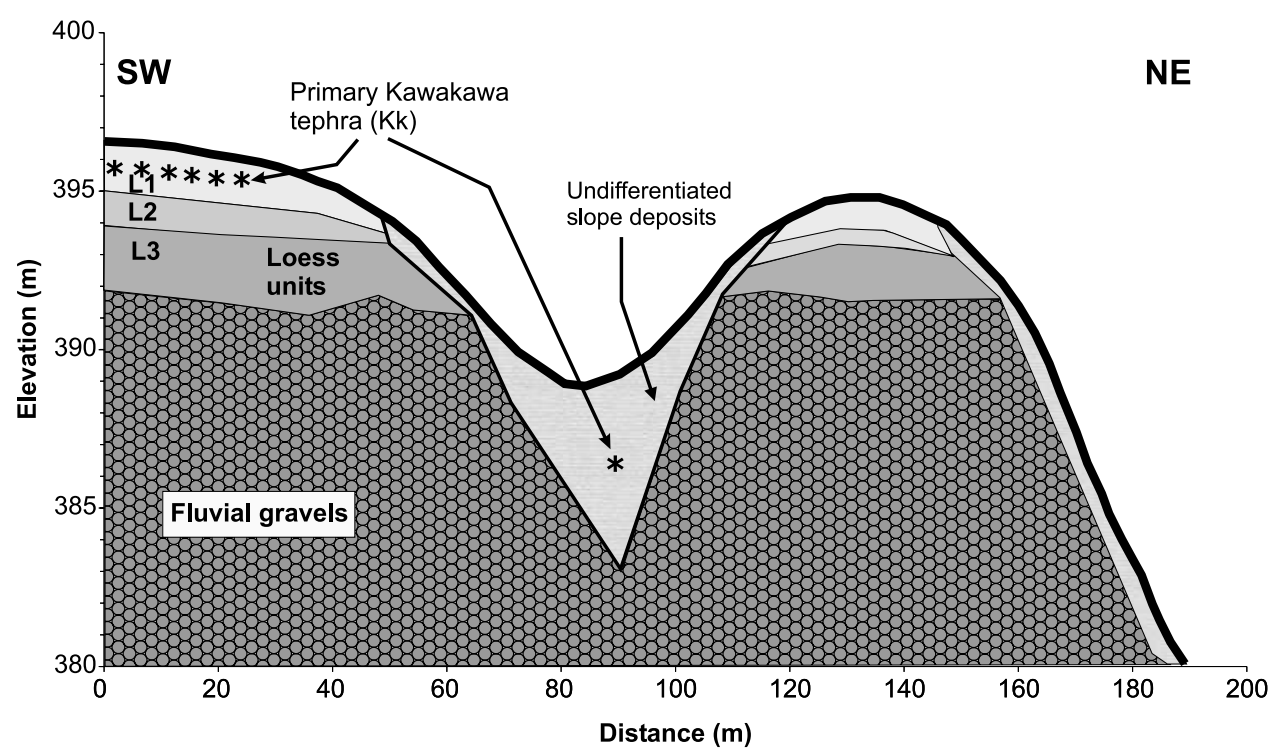

Figure 8. Summary of soil stratigraphic data gathered along our study transect in the Dillondale surfaces. At least three loess units (totaling over $5 \mathrm{~m}$ in thickness) mantle fluvial gravels. Primary tephra (Kawakawa, $26.5 \mathrm{ka}$ ) was emplaced during a period of loess production and can be found concentrated near the transect top $(x=0-30 \mathrm{~m})$ and at $4 \mathrm{~m}$ depth in the valley deposits $(x=90 \mathrm{~m})$.

penultimate glacial advance. These surfaces have a more rounded and dissected appearance. Local relief in the Dillondale unit is zero in the undissected terrace interiors and approaches $30 \mathrm{~m}$ near the valley outlets. In Figure 7, beyond the Dillondale surfaces and in front of the high ridgeline, highly dissected remnants of the Quail Downs surfaces are just visible. This surface is altered to the extent that little if any of the original terrace treads remain; most have been dissected and rounded by erosional processes. Contemporaneous with periods of aggradation, loess production was widespread in the region [Tonkin and Basher, 1990]. The thickness of loess mantling the fluvial gravels depends on both the age and morphologic character of the terrace surfaces. Whereas older surfaces have been subject to more periods of loess production, these surfaces do not harbor loess deposits. This may reflect removal of loess by hillslope processes on such dissected slopes.

[25] Currently, the study area is covered by grassy pasture. This region has been grazed over the past $100+$ years, yet no evidence of significant erosion by overland flow is apparent. Furthermore, we hypothesize that modern climatic and vegetative conditions (wet and lowroot reinforcement) would be more conducive to erosion by overland flow than conditions associated with the LGM (which was drier, with more densely rooted vegetation). Palynological data from nearby areas [Burrows and Russell, 1990; McGlone and Basher, 1995] indicate that deep-rooted grasses dominated the area during the LGM. In the 2-3 kyr preceding the Holocene transition a shrub-dominated regime prevailed. Extensive forests, including podocarp (Podocarpaceae) and beech (Nothofagus) trees, became prominent following the Holocene transition and persisted until widespread burning by indigenous peoples about 700 years ago. These trees have a typical rooting depth of $\sim 0.5 \mathrm{~m}$, according to a recent study [Hart et al., 2003].

[26] We focused our analysis of hillslope evolution on remnants of the Dillondale surface because this unit has experienced early stages of drainage development; flat, undissected terrace surfaces are connected to low-gradient valleys by broadly convex hillslopes (Figure 7). In effect, the Dillondale surface offers an opportunity to characterize a transient phase in the evolution of hilly terrain. The role of climate change in dictating erosional response in these systems has not been well quantified.

\section{Soil Stratigraphy}

[27] To characterize the late Quaternary pattern of hillslope response, we conducted a detailed soil stratigraphic study along a 200-m-long hillslope/valley transect in the Dillondale surface (Figure 8). Our transect has negligible planform curvature, validating the use of one-dimensional measurements and modeling. We used hand and power augers, drill cores, and trenching to document soil properties. At least three distinct loess units (totaling over $5 \mathrm{~m}$ in thickness) mantle the Dillondale aggradation gravels. The loess is quartzo-feldspathic, dominantly derived from erosion products of Torlesse sandstones and argillites. Soils in loess sheet 1 (Fragic Epiaqualfs) are characterized by silt loam A and upper B horizons, with evidence of seasonal saturation, above a dense, oxidized, clay-rich subsoil. Between 40 and $65 \mathrm{~m}$ along the transect shown in Figure 8 , the slope successively crosscuts loess sheets 2 and 3 in the downslope direction. Over this slope segment, soils (Typic Paleudalfs) are composite, formed from 40$50 \mathrm{~cm}$ of silty loess over a clay-rich subsoil comprising the buried soil in loess sheet 3 . The buried soil in loess sheet 3 is strongly weathered, and soils are clay-rich between 45 and $60 \mathrm{~m}$ along the transect. The thick wedge of colluvium in the valley between 70 and $100 \mathrm{~m}$ along the transect is composed of undifferentiated deposits, presumably recording infilling from sideslopes. Here the depth to fluvial gravels is $>5 \mathrm{~m}$, reflecting a rich history of valley incision and infilling. 
[28] Kawakawa tephra (26.5 ka, calibrated calendric age) from the Taupo volcanic zone (TVZ) in the North Island (see Figure 6) is one of the most widespread late Pleistocene volcanic marker beds in New Zealand [Palmer, 1982; Pillans et al., 1993]. It can be identified visually throughout the North Island and in sites favorable for preservation in the northern half of the South Island. At our site, it occurs microscopically (indiscernible to the naked eye) as glass grains within soils of loess sheet 1 and near the base of the valley fill (Figure 8), indicating that it was deposited during a period of loess production. Individual tephra grains do not exhibit signs of chemical alteration and are readily differentiable from loess particles, making them a useful tracer for tracking the movement of soil.

\section{Hillslope Morphology and Tephra Distribution}

[29] We documented hillslope morphology and depth profiles of tephra concentration along our study transect to characterize sediment transport mechanisms and quantify how climate change may have impacted erosional response. Figure 9a illustrates hillslope morphology and the locations for our soil cores (labeled with letters $\mathrm{A}-\mathrm{H}$ ) in relation to the underlying soil stratigraphy (loess units are labeled L1, L2, and L3). We surveyed elevations every few meters along the hillslope transect using a total station and calculated topographic derivatives by fitting a second-order polynomial to a patch of local elevation points at several locations along the profile (Figure 9b). The coefficients of the best fit polynomials were used to estimate gradient and curvature.

[30] The southwest end of the study transect is undissected and has low values of gradient and curvature (Figure 9b). In the downslope direction the hillslope steepens, generating a convex form. The trend of the downslope increase in gradient is nonlinear such that values of curvature become increasingly negative. According to equation (1), this distribution of curvature and gradient indicates that erosion rates should be greatest near the valley margin $(x=50-55 \mathrm{~m})$ and decrease upslope. This pattern is consistent with early stages in the development of relief (as shown in Figures $4 \mathrm{a}$ and $4 \mathrm{~b}$ ), reflecting the development of hillslopes following incision of an initially flat surface. Near the valley margin the trend in gradient reverses as the slope flattens into the valley bottom. Values of curvature switch sign at $x=60-65 \mathrm{~m}$, as the convexity of the upper slope gives way to concavity of the valley floor. In the absence of base-level lowering, equation (1) predicts deposition at this location along the transect. The thick wedge of soil supports this result and suggests that recent deposition from upslope has outpaced removal by fluvial processes.

[31] At nine locations along the hillslope transect we collected continuous-core auger samples of the upper $\sim 1 \mathrm{~m}$ of soil to estimate the concentration of tephra with depth. Using a laboratory procedure developed by P. Almond (manuscript in preparation, 2004), we determined the concentration of tephra grains in the $63-350 \mu \mathrm{m}$ fraction, which nearly constitutes the majority of all tephra grains at this locale. Individual tephra grains do not exhibit perceptible alteration, confirming the utility of the tephra as a conservative tracer at this site. Because our analysis only documents tephra grains within a given size fraction, we assume that these grains are representative of the total mass

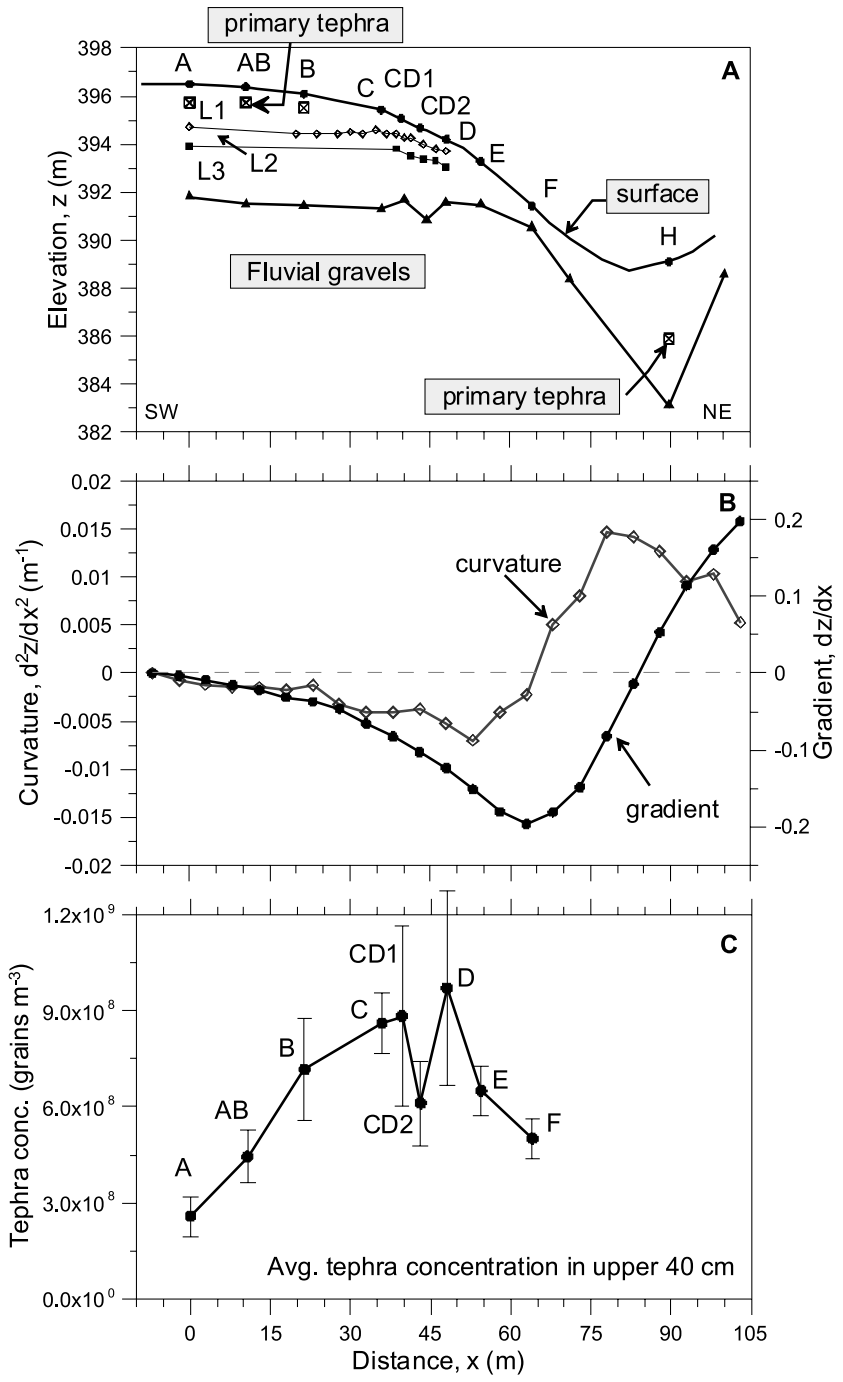

Figure 9. (a) Detailed topographic and soil stratigraphic profiles for a portion of the study transect. The letter labels denote the locations of continuous-core soil samples of the upper $1 \mathrm{~m}$. At each of these sites we documented the depth variation of tephra concentration. L1, L2, and L3 refer to successive loess units, as identified by soil properties. The paleohillslope profiles, as shown by the loess unit geometry, were flatter and more "kinked" than the current profile. (b) Topographic derivatives calculated along the study transect. Near the crest $(x=0)$, gradient is zero, increasing in the downslope direction before reaching a maximum at $x=63 \mathrm{~m}$ and then decreasing into the valley. Curvature values indicate an increasing convexity downslope, reaching a maximum value at $x=50-55 \mathrm{~m}$ and then approaching zero and positive (concave) values into the valley bottom. According to equation (1), curvature is roughly proportional to erosion rate for low gradients. As a result, this profile portrays a hillslope in transition, with the greatest erosion rates just upslope of the valley margin and then decreasing to zero near the hillcrest. A similar pattern is predicted for hillslopes that developed from incision into a flat, low-relief initial surface. (c) Depth-averaged tephra concentration in the upper, mobile soil layer (calculated for the upper $40 \mathrm{~cm}$ ) for each core along the profile. High values in the midslope section reflect recent exhumation of the primary tephra layer. 

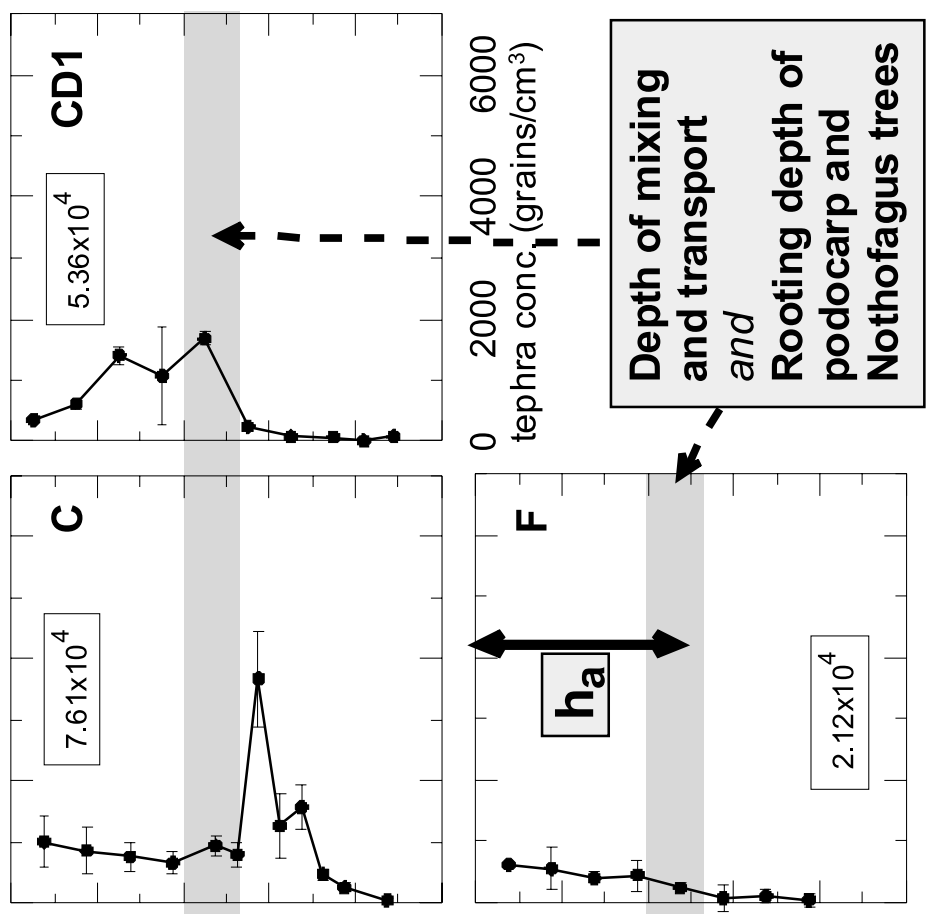

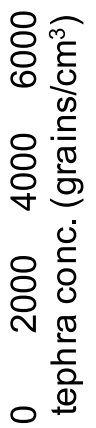

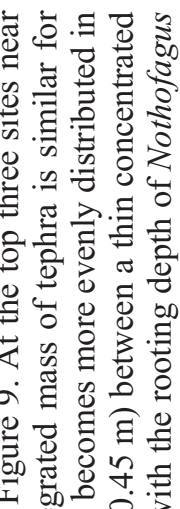

I
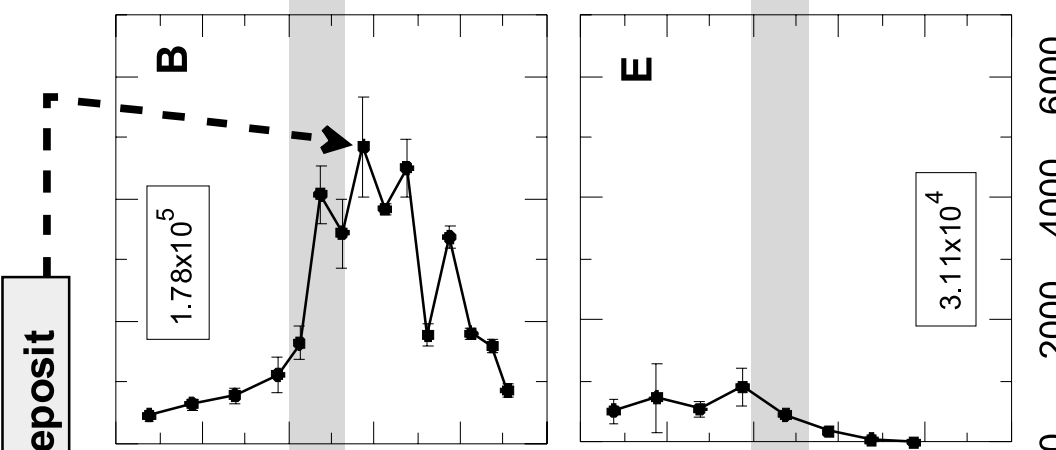

융

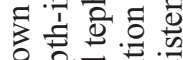

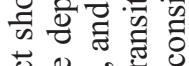

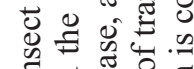

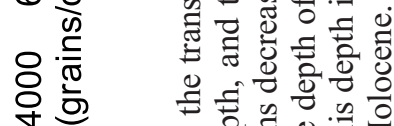

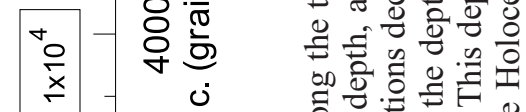

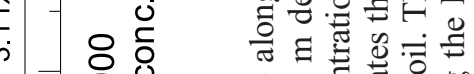

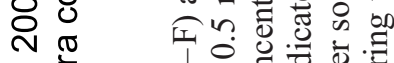

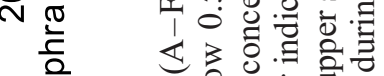

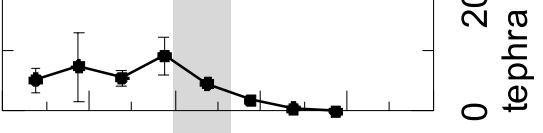

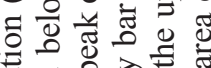
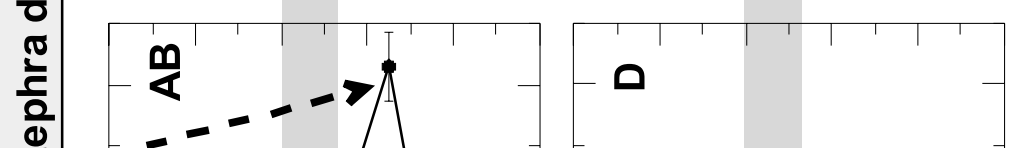

৪)

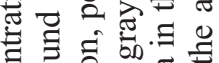

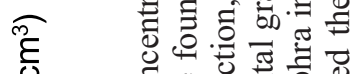

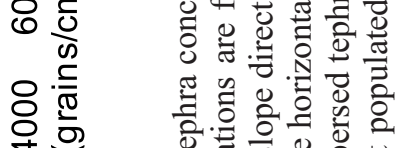

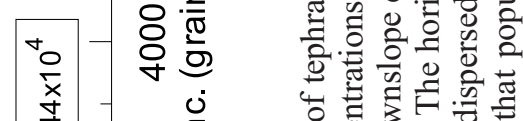

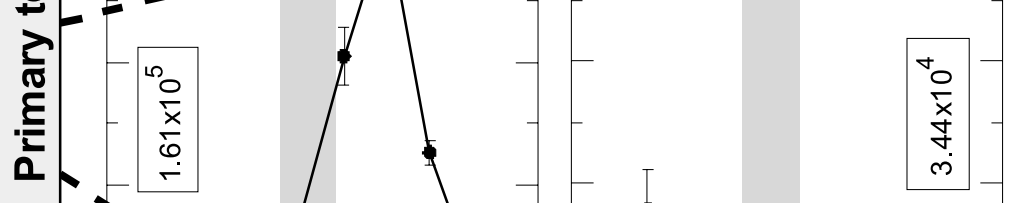

8 잉

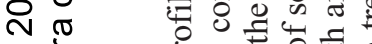

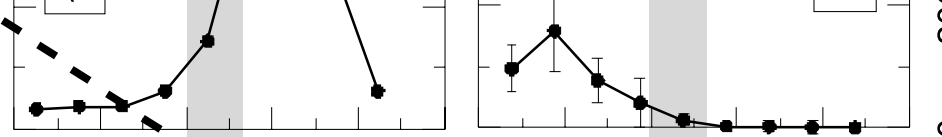

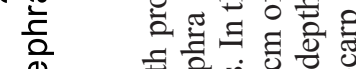

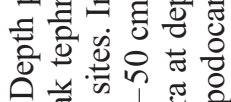

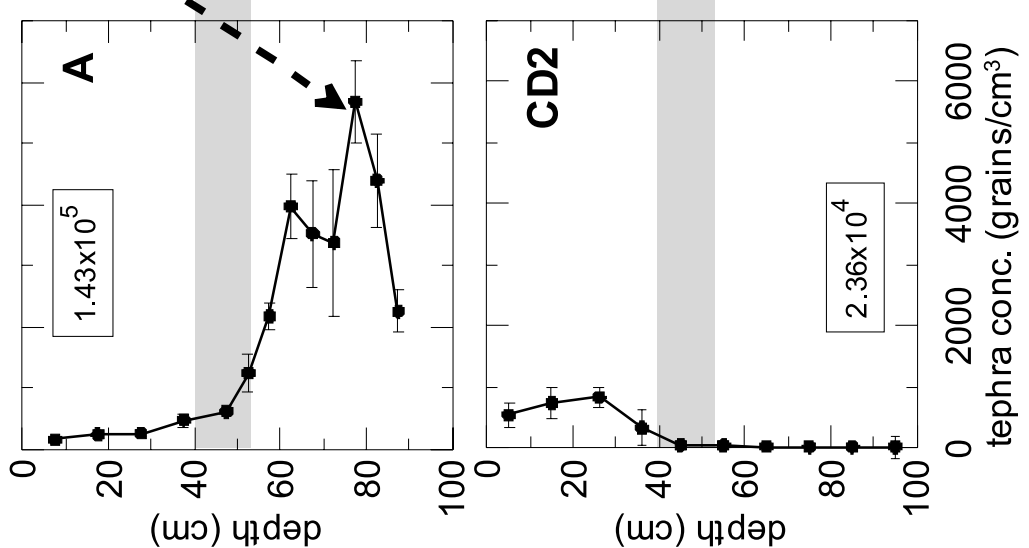

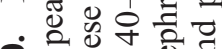

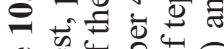

넌

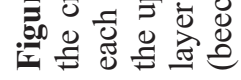


of tephra within each soil core. At the upper three sites (A, $\mathrm{AB}$, and $\mathrm{B}$ ) we observed concentrated tephra at depths ranging from 0.6 to $0.8 \mathrm{~m}$ (Figure 10). We interpret these concentration spikes as the primary tephra deposit emplaced during a period of loess accumulation. Subsequent soil upbuilding associated with continued loess deposition [Almond and Tonkin, 1999] caused variable quantities of tephra grains to be incorporated into the upper soils due to mixing by grasses and soil mesofauna (site A, Figure 10). As described by Roering et al. [2002], the depth to the concentration spike decreases in the downslope direction along sites $\mathrm{A}, \mathrm{AB}$, and $\mathrm{B}$, coincident with a linear increase in hillslope convexity (Figure 9b). We suggest that this pattern represents progressive exhumation of tephra driven by the upslope propagation of slope adjustment due to base-level lowering.

[32] At sites $\mathrm{C}-\mathrm{F}$ the concentration spike is not readily apparent, and the depth-integrated mass of tephra is $50 \%$ less than that measured at sites $\mathrm{A}, \mathrm{AB}$, and $\mathrm{B}$ (see Figure 10). Moving from site B to CD1, the spike becomes indistinguishable, and most of the tephra is found dispersed in the upper soil. Farther downslope, the tephra grains are uniformly distributed within the upper soil, and concentrations below $50 \mathrm{~cm}$ are negligible. Along our study transect the transition between a thin concentrated layer of tephra at depth and dispersed tephra in the upper soil occurs at a depth of $\sim 40-50 \mathrm{~cm}$. We suggest that this transition results from the combined effects of increasing erosion (and thus exhumation) in the downslope direction and disturbancedriven mixing, disruption, and transport of soils in the upper $40-50 \mathrm{~cm}$ of soil. We attribute the mixing and transport to bioturbation (including root growth and tree turnover) associated with trees that populated the area during most of the Holocene. The rooting depth of the Nothofagus and podocarp trees is $\sim 50 \mathrm{~cm}$, consistent with the observed depth of transition between disturbed and undisturbed soil and tephra grains. Stochastic bioturbation [e.g., Heimsath et al., 2001] may drive soil transport at our site, resulting in well-mixed soils (and tephra grains) in the mobile layer.

[33] To characterize the pattern of exhumed and transported tephra grains along the transect, we estimated mean concentrations in the upper $40 \mathrm{~cm}$ of each soil core (Figure 9c). The average distribution of tephra in this upper, mobile soil layer reflects both mixing during late Pleistocene loess accumulation in a grassland ecosystem and subsequent exhumation and transport in the Holocene forested ecosystem. For example, at sites $\mathrm{A}, \mathrm{AB}$, and $\mathrm{C}$ the primary tephra deposit has not been fully exhumed into the active soil layer, yet we observe tephra grains in the upper layer. These low concentrations reflect mixing associated with tephra emplacement and loess accumulation. In the middle of the transect (Figure 9c), high concentrations in the upper $40 \mathrm{~cm}$ reflect recent exhumation of the primary tephra layer (see sites C, CD1, CD2, and D). Farther downslope, the decrease in concentration indicates that tephra has been exhumed, significantly reworked, and transported downslope (sites E and F).

\section{Application of Coupled Soil/Tracer Transport Model}

[34] We applied the coupled soil/tracer model to our Dillondale hillslope profile to explore the pattern of slope adjustment and to constrain the influence of climate-driven variations in transport efficiency. The average concentration of tephra in the upper, mobile soil layer exhibits a humped pattern, with low concentrations along the upper and lower slope segments and high concentrations in the midslope region (Figure 9c). While our analyses cannot address the detailed characteristics of tephra redistribution along our hillslope transect (Figure 10), our coupled transport model may allow us to quantify rates of soil transport necessary to reproduce the general pattern and magnitude of tephra concentration in the mobile soil layer.

\subsection{Model Setup and Initial Conditions}

[35] First, we constrained the characteristics of our study area, including climate history, initial hillslope, and tephra layer geometry. For simplicity, we chose to begin our simulation when loess production atop the Dillondale gravels began to subside and subsequent modification of the topographic surface was predominantly associated with soil transport and erosion. The decline of loess production must postdate the Kawakawa tephra $(26.5 \mathrm{ka})$, which was emplaced within loess sheet 1 (Figure 8). Near the end of the LGM $(\sim 18 \mathrm{kyr})$, rates of gravel aggradation were high, and nearby grass-mantled slopes were an effective trap for mobile and abundant eolian deposits. Wetter conditions beginning around 13-14 kyr resulted in the spreading of tall shrubs [Bull, 1991; McGlone et al., 1993] and likely coincided with the decline of significant loess deposition. Rates of loess production are demonstrably low during the Holocene. Considering this history, we begin the simulation at $13 \mathrm{kyr}$, when grasses and shrubs covered the hillslopes, contributing to disturbance and transport of soils. Since the LGM, the valley at the base of our study transect has aggraded as revealed by the thick infill of undifferentiated loess.

[36] The loess stratigraphy shown in Figure 9a provides an indication of pre-Holocene ( $13 \mathrm{kyr})$ hillslope geometry. In contrast to the broad convex nature of the current topography, the loess units reveal a flatter interfluve, with a discrete change in slope at $x=35-40 \mathrm{~m}$. Because erosion has been negligible at site A, we estimated the geometry of the $13 \mathrm{kyr}$ hillslope by replacing the full, uneroded thickness of loess unit L1 $(1.8 \mathrm{~m})$ atop the L1/L2 boundary. Additional soil cores collected near our study site indicate that $1.8 \mathrm{~m}$ is a consistent estimate of the full thickness of L1. Notably, the L1/L2 interface exhibits a distinct "kink" at $x=35-40 \mathrm{~m}$. Downslope, the L1/L2 interface becomes indistinguishable, although additional observations aid in the interpretation of the pre-Holocene hillslope geometry. The emergence of gravels near the modern surface at $x=$ $65 \mathrm{~m}$ and the occurrence of primary Kawakawa tephra $4 \mathrm{~m}$ below the surface of the valley floor (Figure 9a) indicate that the lower section of the transect was steeper than upslope sections. Using these constraints, we estimated the form of the $13 \mathrm{kyr}$ hillslope (Figure 12a). The uncertainty of our reconstructed hillslope is low $(<0.1 \mathrm{~m})$ in the upslope sections $(x<45 \mathrm{~m})$ and increases along the lower section $(<0.4 \mathrm{~m})$.

[37] The $13 \mathrm{kyr}$ subsurface distribution of tephra is approximated by the concentration profiles at sites $A, A B$, and $\mathrm{B}$. We characterized the initial distribution by fitting a normal distribution to the depth profile of tephra concen- 


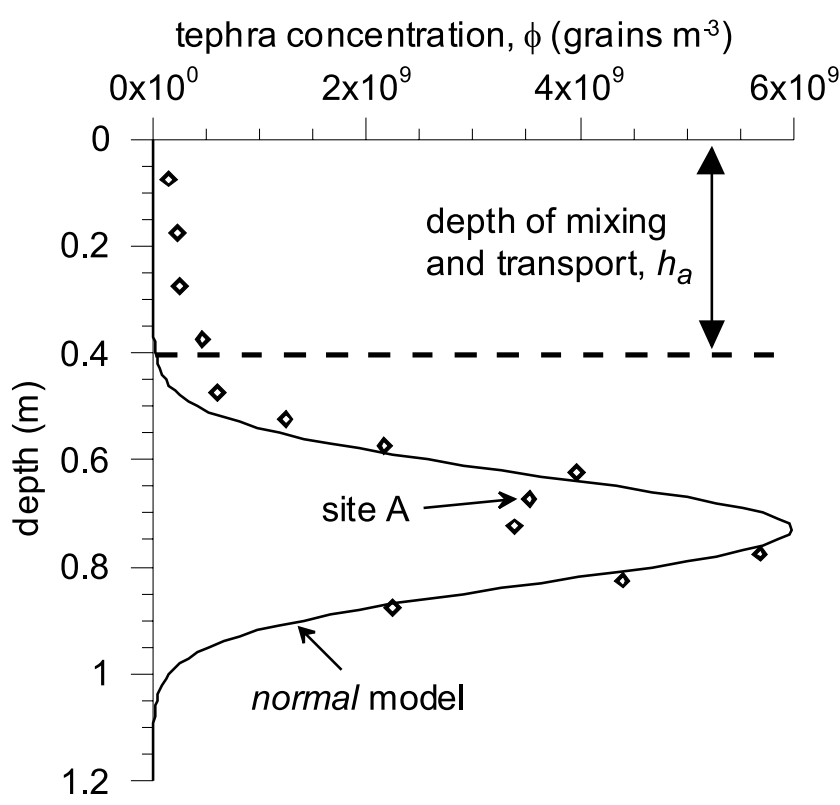

Figure 11. Variation of tephra concentration with depth for site A (shown with open diamonds) and a normal distribution function used to the represent the subsurface tephra for our simulation (shown with the thin black line). The normal distribution with depth (or mean) equal to $0.75 \mathrm{~m}$ and a standard deviation of $0.1 \mathrm{~m}$ appears to fit the data well, apart from deviations in the upper $0.4 \mathrm{~m}$ (see text for explanation).

tration at site A (Figure 11). Apart from localized deviations, the normal model with peak concentration at $0.75 \mathrm{~m}$ depth and standard deviation $(\sigma)$ equal to $0.1 \mathrm{~m}$ is used to represent the observed distribution. We specified this modeled depth profile of tephra concentration at each node along the initial (13 kyr) hillslope.

[38] We specified a "no erosion" boundary condition at the upper node of our model hillslope $(x=0)$, whereas the lower boundary $(x=90 \mathrm{~m})$ was subject to aggradation consistent with our field observations (Figures 8 and 9). Because our simulations were motivated toward deciphering erosional response along the upper slope, where our observations of tephra concentration are dense, we only present results along the upper $70 \mathrm{~m}$ of the model hillslope.

[39] To simulate the climatic influence on erosional processes, we evolved the model hillslope, varying the value of $K$ with time. The initial value $\left(K_{\mathrm{LP}}\right)$ is associated with the late Pleistocene grass/shrub-dominated period (from 13 to $10 \mathrm{kyr}$ ), and a second value $\left(K_{\mathrm{H}}\right)$ represents the forested Holocene period (10 kyr to present). We explored numerous combinations of $K$ values to determine their influence on the observed topography and tephra concentration pattern. For this study we set the depth of active transport $\left(h_{a}\right)$ equal to $0.45 \mathrm{~m}$ (consistent with observations of tree rooting depth) for both vegetation periods because physiological data for the grass/shrubdominated system is lacking.

\subsection{Results}

[40] Our simulations portray a hillslope evolving from a flat and rectilinear form to a broadly convex morphol- ogy (Figure 12a). Given sufficient landscape lowering, our results indicate that exhumed tephra grains in the mobile soil layer become concentrated in the midslope zone, where a wave of high concentration begins to propagate in the upslope and downslope directions (Figure 12b).

\subsubsection{Parameter Calibration}

[41] We estimated the values of best fit transport parameters necessary to produce the current topography and the pattern of tephra redistribution by comparing observed topographic (Figure 9a) and mean tephra concentration data (Figure 9c) with simulation results. We performed a grid search of various $K_{\mathrm{H}}$ and $K_{\mathrm{LP}}$ combinations, calculating the root-mean-square error (RMSE) of observed and modeled topographic (Figure 12a) and concentration (Figure 12b) profiles. Figure 13a shows the distribution of RMSE for modeled and observed elevation. The pattern of surface lowering required to match the current topography can be achieved with various combinations of $K_{\mathrm{LP}}$ and $K_{\mathrm{H}}$. The misfit surface determined by comparing observed and modeled values of tephra concentration in the upper $40 \mathrm{~cm}$ of soil shows a similar result (Figure 13b), although the form of the misfit surface (which we normalized by the maximum RMSE value) is considerably more asymmetric than that shown in Figure 13a. The asymmetry of the tephra misfit surface arises because the emergence of tephra grains occurs over relatively short time intervals. In other words, model parameters are highly sensitive to the timing and pattern of tephra exhumation. Our analyses do not define a unique combination of parameter values; instead, we observe a linear band of low RMSE values that define the range of best fit values of $K_{\mathrm{H}}$ and $K_{\mathrm{LP}}$ (Figure 13).

\subsubsection{Hillslope Geometry}

[42] Results for the simulation with $K_{\mathrm{LP}}=0.001 \mathrm{~m}^{2} \mathrm{yr}^{-1}$, $K_{\mathrm{H}}=0.016 \mathrm{~m}^{2} \mathrm{yr}^{-1}$, and $S_{c}=1.25$ are shown in Figure 12 . We set $K_{\mathrm{LP}}$ to this arbitrarily low value, recognizing that the simulation results are relatively insensitive to its exact value; instead, the results are highly sensitive to the integral of the transport rate constant $(K)$ and the time period $(t)$, calculated for the entire simulation. Elevation values attained at the simulation conclusion $(t=0 \mathrm{ka})$ are similar to the observed hillslope profile (Figure 12a). Along the upper slope segment, surface lowering is small yet distinguishable, consistent with the pattern of progressive downslope exhumation of the concentrated tephra layer shown at sites $\mathrm{A}$ to $\mathrm{AB}$ to $\mathrm{B}$ (see Figure 10). In the downslope direction, erosion increases, reaching a maximum in the midslope section, coincident with the location of slope breaks in the initial hillslope geometry. Figure $12 \mathrm{c}$ shows the temporal variation of $K$ and the median curvature value of the model hillslope. The initial period, with $K=0.001 \mathrm{~m}^{2} \mathrm{yr}^{-1}$, does not generate significant slope alteration, whereas the onset of Holocene forested conditions readily sculpts the topography, increasing hillslope convexity.

[43] If bioturbation-driven transport rates associated with forested Holocene conditions were higher than those during the grass-dominated and shrub-dominated late Pleistocene, it is likely that $K_{\mathrm{H}} \gg K_{\mathrm{LP}}$. This hypothesis is supported by the rectilinear geometry of paleohillslope surfaces revealed by loess stratigraphy at our site (Figure 9a). The angularity 

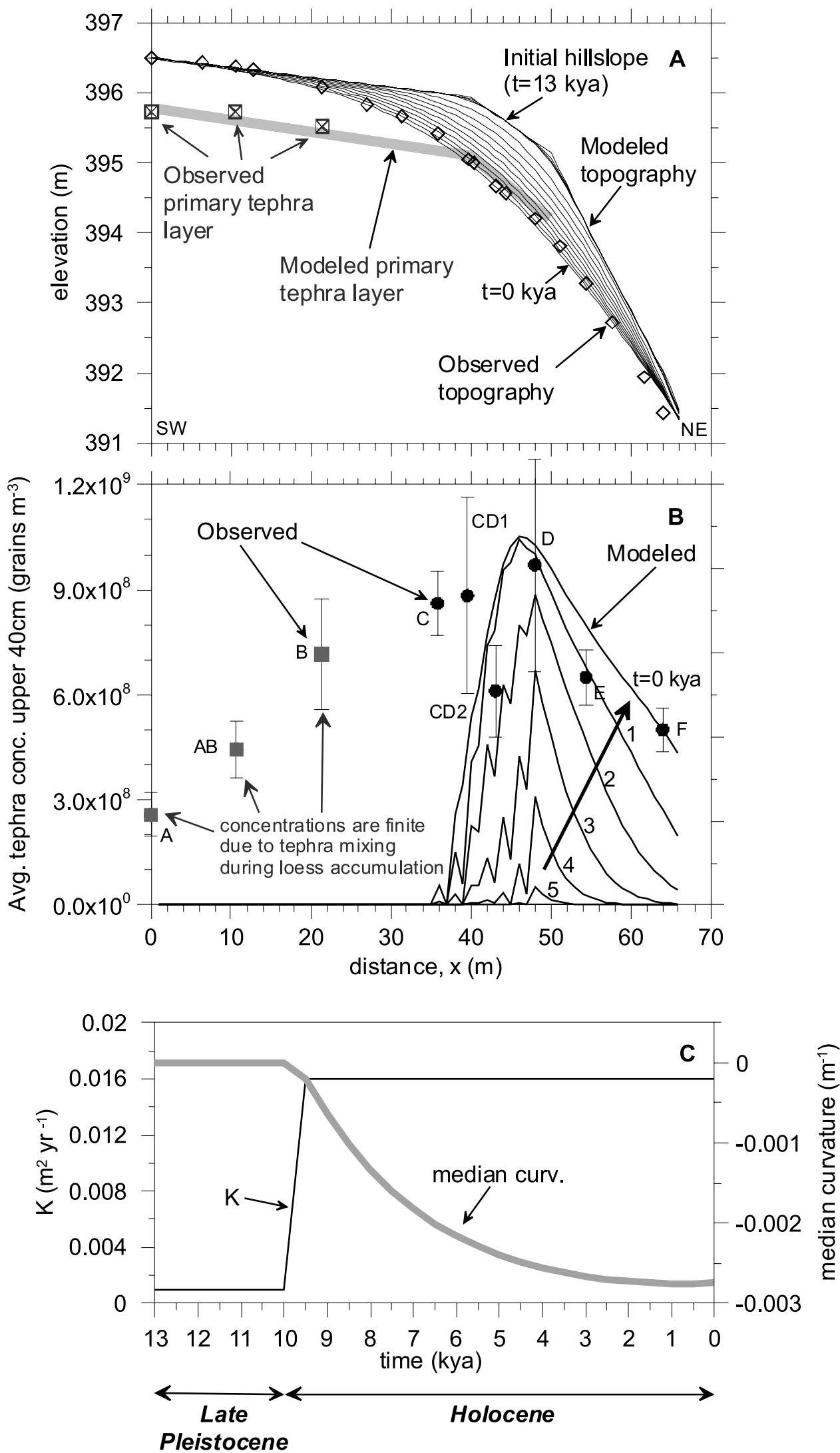

Figure 12. 
of these late Pleistocene surfaces suggests that transport rates were relatively low in comparison to those responsible for sculpting the broadly convex surface we observe today. Given the requirement that $K_{\mathrm{H}} \gg K_{\mathrm{LP}}$, the set of acceptable $K$ combinations is significantly reduced.

\subsubsection{Tephra Concentration Along Transect}

[44] While observed and modeled tephra concentrations are in general agreement along the lower slope, observed values along the upper slope are finite where the model predicts that concentrations are zero $(0<x<35 \mathrm{~m}$ in Figure 12b). As noted earlier, these upper sites (A, AB, and B) contain primary tephra deposits below $40 \mathrm{~cm}$ that are effectively isolated from the mobile soil layer. However, mixing during periods of loess accumulation in a grassland regime most likely led to the incorporation of tephra particles in the upper soil at these sites (see Figures 10 and 11) [Almond and Tonkin, 1999]. As a result, average concentration values in the upper $40 \mathrm{~cm}$ for these sites (Figure 12b) are nonzero despite the fact that the primary tephra deposit has remained relatively undisturbed during the Holocene. Thus in comparing observed and modeled tephra concentration values, we did not include the three sites $(\mathrm{A}, \mathrm{AB}$, and $\mathrm{B})$ in our calibration.

[45] Consistent with observed tephra concentration profiles, our simulation results predict that the layer of concentrated tephra has emerged and become incorporated into the mobile regolith between $x=35$ and $x=50 \mathrm{~m}$ along the transect. In addition, the magnitude and pattern of observed and modeled concentration values are consistent along the lower slope. At the simulation conclusion, observed and modeled tephra concentration values are greatest in the midslope region $(40<x<50 \mathrm{~m})$, which corresponds to the zone of maximum lowering and maximum convexity (negative curvature) in the modern profile (Figure 9b). This result suggests that the zone of maximum tephra concentration records the location of maximum paleohillslope convexity. The emerging wave of mobilized tephra in the active layer has an asymmetric form (Figure 12b). The steep, upslope side reflects the rather sharp boundary between areas with exhumed (midslope, $x=40-50 \mathrm{~m}$ ) and unexhumed (upslope, $x=0-30 \mathrm{~m}$ ) primary tephra deposits. The upslope side of the modeled concentration wave demarcates the leading edge in the "unzippering" of the buried tephra deposit. The downslope side of the modeled wave has a gentler slope because transport from upslope supplies tephra to these segments, suppressing large concentration gradients.

\section{Discussion}

[46] During the Holocene, bioturbation in the upper 0.4 to $0.5 \mathrm{~m}$ of soil in our study area resulted in vigorous mixing and net downslope transport. Several soil stratigraphic studies suggest that forested soil horizonation is largely controlled by the accumulated effect of "floral pedoturbation" [ Lutz, 1960; Lutz and Griswold, 1939; Schaetzl, 1986; Schaetzl et al., 1990; Small et al., 1990]. Denny and Goodlett [1957, p. 64] suggest that in their low-gradient study area, tree toppling and the associated soil disturbance "must have caused downslope movement of the mantle at a rate faster than that produced by all other processes combined." By extrapolating observations of tree spacing and turnover, they calculated a soil flux rate $\left(\sim 0.001 \mathrm{~m}^{2} \mathrm{yr}^{-1}\right)$ along a low-gradient forested slope [Denny and Goodlett, 1957]. Although the exact gradient of their site was not reported, their result suggests that the transport rate constant $(K)$ was of similar magnitude to the value we estimate here $\left(\sim 0.01 \mathrm{~m}^{2} \mathrm{yr}^{-1}\right)$. Rates of tree turnover are thought to be frequent enough that the length of time during which $50 \%$ of the soils in a forest are turned over is on the order of hundreds to thousands of years, depending on forest density, tree longevity, and disturbance mechanisms [Norton, 1989]. Data gathered from recent tree throw sites in the Oregon Coast Range indicate that an average of nearly $4 \mathrm{~m}^{3}$ (and up to $15 \mathrm{~m}^{3}$ ) of soil and rock are displaced during each event [Mort, 2003], attesting to the efficiency of sediment transport in forested environments. The transport coefficient $(K)$ encapsulates how the frequency, magnitude, and behavior of disturbances affect sediment transport, and a more explicit treatment of these variables will enable us to predict how different vegetation assemblages modulate sediment production.

[47] The value of $K_{\mathrm{H}}\left(0.016 \pm 0.005 \mathrm{~m}^{2} \mathrm{yr}^{-1}\right)$ estimated from our coupled model results is similar to previous estimates in forested landscapes [Nash, 1980] and is similar to the value $\left(0.012 \pm 0.008 \mathrm{~m}^{2} \mathrm{yr}^{-1}\right)$ derived from analyzing surface lowering relative to the primary tephra layer at sites $\mathrm{A}, \mathrm{AB}$, and $\mathrm{B}$ (Figure 10) and topographic derivatives calculated at those locations [Roering et al., 2002]. The similarity of these independent estimates lends support to our slope-dependent transport model.

Figure 12. (a) Evolution of elevation along our study site transect, beginning with $t=13$ ka and concluding with $t=0$ ka. Profiles intervals are $1 \mathrm{kyr}$. The surveyed profile is shown by open diamonds. The observed primary tephra unit is denoted by a thick gray band. The initial hillslope geometry was generated using the soil stratigraphic data shown in Figure 9. (b) Evolution of depth-averaged (upper $40 \mathrm{~cm}$ ) tephra concentration along the hillslope shown in Figure 12a. Observed values are shown by black circles and gray squares. High concentration values occur between 45 and $55 \mathrm{~m}$ along the transect, coincident with the points of high curvature in the initial hillslope geometry. Observed tephra concentration values in the upslope segment (in the range $x=0-25 \mathrm{~m}$ ) are finite because of mixing during the late Pleistocene period of loess accumulation and soil upbuilding. As a result, we compare our observed and modeled values along the lower slope segment for parameter estimation purposes. Our data (see Figure 10) and model results are consistent in that upslope sites $(0<x<$ $25 \mathrm{~m}$ ) exhibit undisturbed tephra below the active soil layer, whereas at sites below downslope of $x=30$, tephra has been sufficiently exhumed such that mixing and disturbance have dispersed it in the upper soil. (c) Time series of $K$ values for the simulation shown in Figures 12a and 12b. For the first $3 \mathrm{kyr}$, low $K$ values represent a grassland-dominated ecosystem. The final 10 kyr represent forested conditions during the Holocene. Values of median curvature (shown by the thick gray line) along the slope become increasingly convex (negative) following the Holocene transition. 

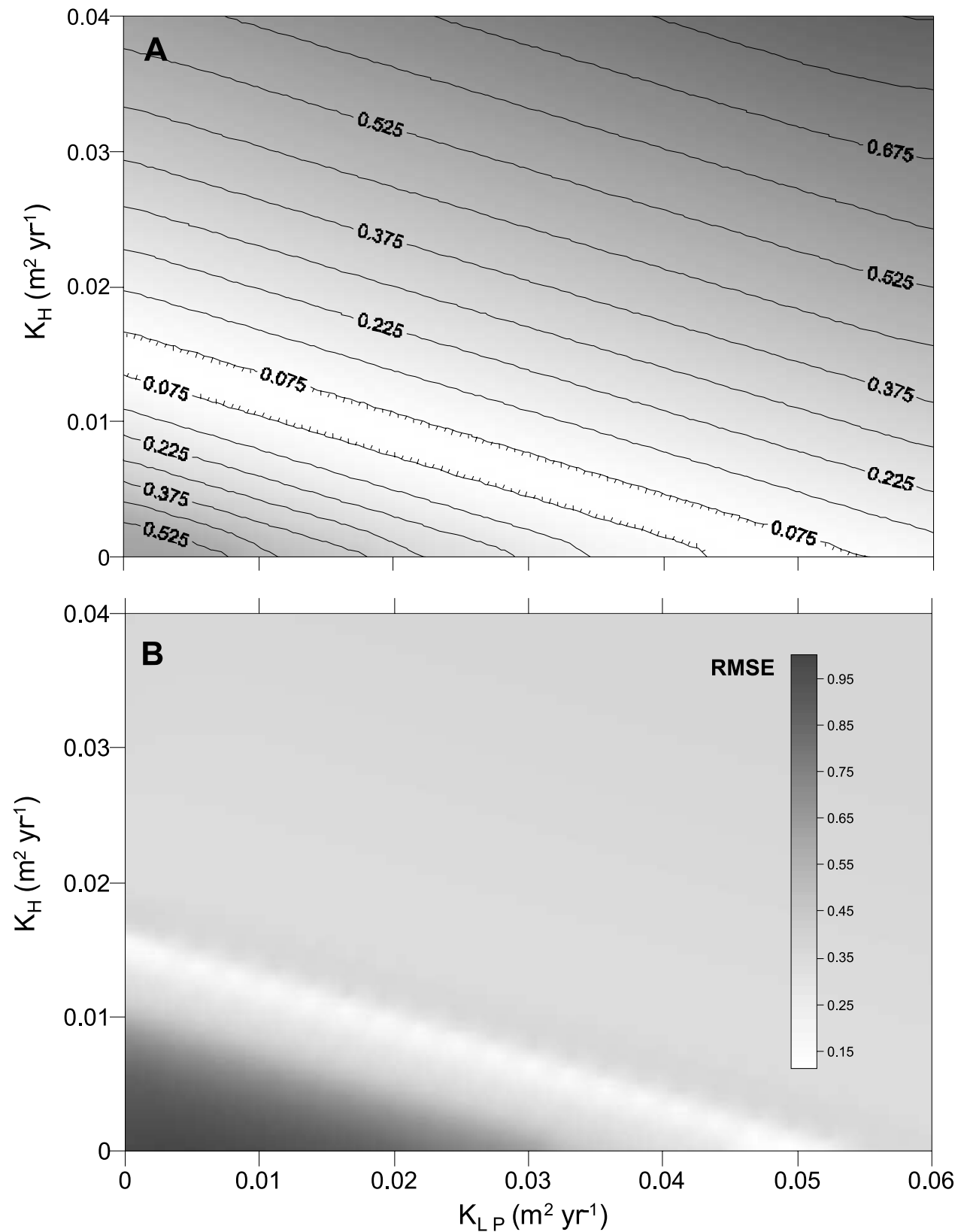

Figure 13. Contour plot of root-mean-square error (RMSE) as a function of $K_{\mathrm{LP}}$ and $K_{\mathrm{H}}$. (a) Variation of RMSE calculated by comparing observed and modeled hillslope profiles (Figure 12a). High values (dark background) define poor model fit, and low values (white background) define values with a low model misfit. The surface does not distinguish a unique set of parameter values; instead, many combinations of $K_{\mathrm{LP}}$ and $K_{\mathrm{H}}$ values can produce the minimum misfit (RSME $=0.06 \mathrm{~m}$ ). The contour interval is $0.075 \mathrm{~m}$. (b) Normalized RMSE surface calculated by comparing observed and modeled tephra concentrations in the upper $40 \mathrm{~cm}$ (Figures 9c and 12a). Values of RMSE are normalized by the maximum RMSE value $\left(6.8 \times 10^{8}\right)$. The linear band of best fit values corresponds well with the misfit surface generated by modeling the topographic surface (Figure 13a).

[48] Quantitative aspects of diffusive systems (e.g., equation (3)) have been well characterized by seismologists interested in back-calculating the timing of coseismic scarp formation. Given an inferred initial scarp geometry, these researchers (see summary by Hanks [2000]) have been able to determine a unique value of $K t$ (where $K$ is the same as that defined in equation (1) and $t$ is time since surface rupture) for degraded scarp profiles. Their estimates of earthquake rupture timing thus depend upon determining an accurate value of $K$. Similarly, given a particular initial condition, the evolution of a hillslope profile can attain the same final form with numerous combinations of $K$ and $t$ (in this case, $t$ is simulation time) provided that the product $K t$ is constant. However, this relationship does not hold when values of $K$ vary through time, as illustrated by our synthetic hillslope simulations (Figure 4). The emergence of morpho- 
logic similarity emphasizes the importance of establishing alternative methods, such as tracers, to quantify the legacy of climate change and other perturbations in landscapes.

[49] In our study site, soil transport during the late Pleistocene did not persist long enough to produce a distinct tephra distribution that can be characterized in terms of a unique combination of $K_{\mathrm{LP}}$ and $K_{\mathrm{H}}$ values. In other words, the length of simulation time was not sufficient to establish distinctive morphologies associated with the two different values of $K$. As a result, various combinations of $K_{\mathrm{LP}}$ and $K_{\mathrm{H}}$ can be used to represent the observed distribution of hillslope topography and tephra concentration, provided that $\int K t d t \cong 160 \pm 30 \mathrm{~m}^{2}$ (Figure 13). Thus our proposed $K$ estimates depend on the stipulation that $K_{\mathrm{H}} \gg K_{\mathrm{LP}}$, which is supported by observations of the differing form of hillslope profiles before and after forest colonization. Nonetheless, given a longer period of pre-Holocene slope degradation, the tephra concentration data could serve as a powerful tool for differentiating the efficacy of erosion processes as a function of climatic regime. The time required to generate a distinct morphologic form associated with a given value of $K$ is determined by the characteristic time $(\tau)$, which varies according to

$$
\tau \propto \frac{L^{2}}{K}
$$

where $L$ is hillslope length (m). According to calculations presented in Roering et al. [2001a], the timescale for hillslope response at our study site is on the order of 10-50 kyr. Thus the short period of $K_{\mathrm{LP}}$ slope modification (from 13 to $10 \mathrm{kyr}$ ) is not sufficient to establish a distinct morphologic signature.

[50] The general correspondence between observed and modeled tephra concentration values supports our conceptual model of rapid and relatively homogeneous mixing of soil by biogenic activity such as root growth and tree turnover (see Figure 2). Tephra particles appear to be well dispersed in the upper soil, inconsistent with soil creep models for which velocities are highest at the surface and decrease rapidly with depth (such that soil velocity profiles have a convex-upward shape). Such models predict that tephra grains should be preferentially removed near the surface and, furthermore, do not include a mechanism for tephra (or any particle) to be recirculated near the base of the actively creeping soil layer. Our tracer transport model (equation (3)) assumes that any ensemble of tracer particles introduced into the upper soil is immediately dispersed, achieving a uniform concentration. In reality, this process likely takes place over tens to hundreds of years, depending on the timescale with which trees or other flora develop, senesce, and decay and the frequency with which they are uprooted by exogenous forces. Regardless, mixing at our site appears to occur on a timescale shorter than that for slope modification by soil transport.

[51] Heimsath et al. [2002] illustrate the application of optical dating to track the frequency with which soil particles visit the surface over thousand-year timescales. Our interpretations are consistent with their conclusion that biogenic disturbances drive soil transport. The timescale of slope adjustment and tracer transport is consistent with the timescale of climatic fluctuations such that we may be able to draw more detailed inferences about how surface processes vary with time.

[52] Our calculations do not address mass loss due to solution, although the modeled Holocene lowering rate at our site is $\sim 0.05-0.1 \mathrm{~mm} \mathrm{yr}^{-1}$, significantly higher than observed rates of solution losses in soil-mantled landscapes, which average $\sim 0.01 \mathrm{~mm} \mathrm{yr}^{-1}$ [Stonestrom et al., 1998]. Furthermore, our calculations do not address erosion associated with overland flow because evidence is lacking, and studies demonstrate that overland flow erosion in many forested areas is primarily associated with roads and disturbed areas [Croke et al., 1999].

[53] Forest colonization in our study area appears to have had a significant impact on the pace of sediment transport processes, transforming broad, flat surfaces with steep margins into broad, convex slopes. Grass/shrub-mantled slopes present during glacial advances may localize hillslope response near areas of incision because rates of soil transport are low. If incision proceeds, slope angles adjacent to valleys may steepen such that shallow slope instabilities result, giving a rectilinear appearance to hillslope profiles. In contrast, forest recolonization appears to increase sediment transport rates significantly such that hillslope response is extensive as soils on gentle slopes experience rigorous detachment and displacement. This transition in transport rates is illustrated in Figure $4 \mathrm{~b}(\operatorname{sim} 2)$, as low initial $K$ values give rise to a locally steepened profile during the first $15 \mathrm{kyr}$ of evolution. After $15 \mathrm{kyr}, K$ is increased, and a broad convexity develops.

[54] The tephra transport model was not calibrated or tuned; the concentration dynamics are completely driven by parameters associated with the soil transport model. Our modeling results are consistent with a flora-induced change in the rate of sediment transport through the late Pleistocene-Holocene transition. High rates of soil transport during the Holocene may be a prominent factor contributing to the infilled character of many low-order valleys across the South Island of New Zealand (e.g., Figure 8). It appears that Holocene conditions favored valley infilling as evidence for active valley incision is sparse.

[55] Previous efforts to model the dependence of erosional processes on climate change and, particularly, on variations in vegetation have generated interesting insights linking hillslope morphology to particular combinations of temperature and precipitation [Kirkby, 1989, 1995]. The dearth of data relating soil transport mechanics to vegetative dynamics has been a hindrance to properly accounting for climatic influences on sediment production [Rosenbloom and Schimel, 1996]. Our results may be used to calculate rates of hillslope evolution as well as track the dynamics of soil organic carbon [Yoo et al., 2001]. Our tephra simulation results also support the use of coupled models for tracking the transport of tracers in soil-mantled systems.

\section{Conclusions}

[56] The model presented here incorporates a novel algorithm for tracking the coupled dynamics of sediment flux and the transport of tracer particles. This methodology may improve our ability to interpret landscape dynamics and, particularly, the influence of climate-related variations 
in erosion rates and mechanisms. Given the results of our simulations, we conclude the following.

[57] 1. Although morphologic criteria are often used to interpret rates of erosion, they may not be able to uniquely distinguish landforms that have evolved under different climatic conditions.

[58] 2. The spatial distribution of tracers in a given landscape provides additional information on landscape history and may improve our ability to decipher system dynamics such as those driven by climate-related changes in erosional processes.

[59] 3. At our New Zealand study site, disturbances associated with biogenic activity (such as tree turnover and root growth) are responsible for dispersing a concentrated layer of tephra once exhumed into the upper $40-50 \mathrm{~cm}$ of soil. The depth separating disturbed and undisturbed deposits is coincident with the rooting depth of the Nothofagus and podocarp trees that colonized the area during the early Holocene.

[60] 4. Transport and mixing of the tephra particles in the active soil layer is well represented by a coupled onedimensional model for the transport of soil and tracers. The modeled evolution of hillslope topography and tephra concentration in the upper soil is similar to our observations. Importantly, the tephra transport component does not include tunable parameters.

[61] 5. The correspondence between observed and modeled tephra distribution supports the use of slope-dependent transport models in soil-mantled landscapes. Although our parameter calibration was unable to uniquely determine transport coefficients associated with late Pleistocene grass/shrub ecosystems $\left(K_{\mathrm{LP}}\right)$ and Holocene forest regimes $\left(K_{\mathrm{H}}\right)$, paleohillslope geometry revealed by loess stratigraphy at our site is consistent with the hypothesis that sediment transport rates associated with forests significantly exceed those associated with grasses and shrubs.

[62] 6. Our estimated value of the Holocene forest-related transport coefficient $\left(K_{\mathrm{H}}=0.016 \mathrm{~m}^{2} \mathrm{yr}^{-1}\right)$ is similar to previous values for forested landscapes and can be used for modeling hillslope evolution and sediment production in other areas in New Zealand.

[63] Acknowledgments. The authors thank Percy Acton Adams for access to paddocks, Bill Bull for sharing background information and insightful observations, David Furbish for sharing his numerical insights, Bill McLea for sharing unpublished palynological data, and Polly Hall for meticulous laboratory work. The paper was greatly improved by constructive and meticulous reviews by D. Furbish, R. Arrowsmith, and an anonymous reviewer. This research was partially funded by the Department of Geological Sciences, University of Canterbury, New Zealand, and by the Soil, Plant, and Ecological Sciences Division, Lincoln University, New Zealand.

\section{References}

Almond, P., and P. Tonkin (1999), Pedogenesis by upbuilding in an extreme leaching and weathering environment, and slow loess accretion, south Westland, New Zealand, Geoderma, 92, 1-36.

Anderson, R. S. (1994), Evolution of the Santa Cruz Mountains, California through tectonic growth and geomorphic decay, J. Geophys. Res., 99, 20,161-20,174.

Anderson, R. S. (2002), Modeling the tor-dotted crests, bedrock edges, and parabolic profiles of high alpine surfaces of the Wind River Range, Wyoming, Geomorphology, 46, 35-58.

Birkeland, P. (1999), Soils and Geomorphology, 448 pp., Oxford Univ. Press, New York.

Blinnikov, M., A. Busacca, and C. Whitlock (2002), Reconstruction of the late Pleistocene grassland of the Columbia basin, Washington, USA, based on phytolith records in loess, Palaeogeogr. Palaeoclimatol. Palaeoecol., 177, 77-101.

Braun, J., A. M. Heimsath, and J. Chappell (2001), Sediment transport mechanisms on soil-mantled hillslopes, Geology, 29, 683-686.

Bull, W. B. (1991), Geomorphic Responses to Climatic Change, 326 pp., Oxford Univ. Press, New York.

Burbank, D. W., J. Leland, E. Fielding, R. S. Anderson, N. Brozovic, M. R. Reid, and C. Duncan (1996), Bedrock incision, rock uplift and threshold hillslopes in the northwestern Himalayas, Nature, 379, 505-510.

Burrows, C. J., and J. B. Russell (1990), Aranuian vegetation history of the Arrowsmith Range, Canterbury: I. Pollen diagrams, plant macrofossils, and buried soils from Prospect Hill, N. Z. J. Bot., 28, 323-345.

Campbell, J. D., and D. S. Coombs (1966), Murihiku supergroup (Triassic to Jurassic) of Southland and South Otago, N. Z. J. Geol. Geophys., 9, $393-398$.

Carson, M. A., and M. J. Kirkby (1972), Hillslope Form and Process, 475 pp., Cambridge Univ. Press, New York.

Cox, T. (1998), Origin of stone concentrations in loess-derived interfluve soils, Quat. Int., 51, 74-75.

Croke, J., P. Hairsine, and P. Fogarty (1999), Sediment transport, redistribution and storage on logged forest hillslopes in south-eastern Australia, Hydrol. Processes, 13, 2705-2720.

Culling, W. E. H. (1960), Analytical theory of erosion, J. Geol., 68, 336344

Davis, W. M. (1992), The convex profile of badland divides, Science, 20, 245.

Denny, C. S., and J. C. Goodlett (1957), Microrelief resulting from fallen trees, U. S. Geol. Surv. Prof. Pap., 288, 59-68.

Dietrich, W. E., R. Reiss, M.-L. Hsu, and D. R. Montgomery (1995), A process-based model for colluvial soil depth and shallow landsliding using digital elevation data, Hydrol. Processes, 9, 383-400.

Dunne, T. (1991), Stochastic aspects of the relations between climates, hydrology and landform evolution, Trans. Jpn. Geomorph. Union, 12(1), $1-24$.

Fernandes, N. F., and W. E. Dietrich (1997), Hillslope evolution by diffusive processes: The timescale for equilibrium adjustments, Water Resour. Res., 33, 1307-1318.

Finlayson, B. L. (1985), Soil creep: A formidable fossil of misconception, in Geomorphology and Soils, edited by K. S. Richards, R. R. Arnett, and S. Ellis, pp. 141-158, Allen and Unwin, Concord, Mass.

Furbish, D. J. (2003), Using the dynamically coupled behavior of landsurface geometry and soil thickness in developing and testing hillslope evolution models, in Prediction in Geomorphology, Geophys. Monogr. Ser., vol. 135, edited by P. Wilcock and R. M. Iverson, pp. 169-181, AGU, Washington, D. C.

Furbish, D. J., and S. Fagherazzi (2001), Stability of creeping soil and implications for hillslope evolution, Water Resour. Res., 37, 2607-2618.

Gabet, E. J. (2000), Gopher bioturbation: Field evidence for non-linear hillslope diffusion, Earth Surf. Processes Landforms, 25, 1419-1428.

Gilbert, G. K. (1877), Report on the geology of the Henry Mountains (Utah), U.S. Geol. Surv., Washington, D. C.

Gilbert, G. K. (1909), The convexity of hilltops, J. Geol., 17, 344-350.

Hack, J. T. (1960), Interpretation of erosional topography in humid temperate regions, Am. J. Sci., 258A, 80-97.

Hanks, T. C. (2000), The age of scarplike landforms from diffusionequation analysis, in Quaternary Geochronology: Methods and Applications, Ref. Shelf Ser., vol. 4, edited by J. S. Noller, J. M. Sower, and W. M. Lettis, pp. 313-338, AGU, Washington, D. C.

Hart, P. B. S., P. W. Clinton, R. B. Allen, A. H. Nordmeyer, and G. Evans (2003), Biomass and macro-nutrients (above- and below-ground) in a New Zealand beech (Nothofagus) forest ecosystem: Implications for carbon storage and sustainable forest management, For. Ecol. Manage., 174, $281-294$

Heimsath, A. M., W. E. Dietrich, K. Nishiizumi, and R. C. Finkel (1997), The soil production function and landscape equilibrium, Nature, 388 , $358-361$.

Heimsath, A. M., J. Chappell, W. E. Dietrich, K. Nishiizumi, and R. C. Finkel (2000), Soil production on a retreating escarpment in southeastern Australia, Geology, 28, 787-790.

Heimsath, A. M., W. E. Dietrich, K. Nishiizumi, and R. C. Finkel (2001), Stochastic processes of soil production and transport: Erosion rates, topographic variation and cosmogenic nuclides in the Oregon Coast Range, Earth Surf. Processes Landforms, 26, 531-552.

Heimsath, A. M., J. Chappell, N. A. Spooner, and D. G. Questiaux (2002), Creeping soil, Geology, 30, 111-114.

Howard, A. D. (1994), A detachment-limited model of drainage basin evolution, Water Resour. Res., 30, 2261-2285.

Howard, A. D. (1997), Badland morphology and evolution: Interpretation using a simulation model, Earth Surf. Processes Landforms, 22, $211-$ 227. 
Johnson, D. L. (1990), Biomantle evolution and the redistribution of Earth materials and artifacts, Soil Sci., 149(2), 84-102.

Kirby, E., and K. Whipple (2001), Quantifying differential rock-uplift rates via stream profile analysis, Geology, 29, 415-418.

Kirkby, M. J. (1971), Hillslope process-response models based on the continuity equation, Inst. Brit. Geogr. Spec. Publ., 3, 15-30.

Kirkby, M. J. (1989), A model to estimate the impact of climatic change on hillslope and regolith form, Catena, 16, 321-341.

Kirkby, M. J. (1995), A model for variations in gelifluction rates with temperature and topography-Implications for global change, Geogr. Ann. Ser. Phys. Geogr., 77A(4), 269-278.

Lutz, H. J. (1960), Movement of rocks by uprooting of forest trees, Am J. Sci., 258, 752-756.

Lutz, H. J., and F. S. Griswold (1939), The influence of tree roots on soil morphology, Am. J. Sci., 237, 389-400.

McGlone, M. S., and L. R. Basher (1995), The deforestation of the upper Awatere catchment, Inland Kaikoura Range, Marlborough, South Island, New Zealand, N. Z. J. Ecol., 19, 53-66.

McGlone, M. S., M. J. Salinger, N. T. Moar, J. E. Kutzbach, T. Webb III, W. F. Ruddiman, F. A. Street-Perrott, and P. J. Bartlein (1993), Paleovegetation studies of New Zealand's climate since the last glacial maximum, in Global Climates Since the Last Glacial Maximum, edited by H. E. Wright Jr. et al., pp. 294-317, Univ. of Minn. Press, Minneapolis.

Mitchell, J. K. (1993), Fundamentals of Soil Behavior, 437 pp., John Wiley, Hoboken, N. J.

Montgomery, D. R. (2001), Slope distributions, threshold hillslopes, and steady-state topography, Am. J. Sci., 301, 432-454.

Mort, M. (2003), Tree-throw and its contribution to soil production in the Oregon Coast Range, M.S. thesis, Univ. of Oreg., Eugene.

Nash, D. B. (1980), Morphologic dating of degraded normal fault scarps, J. Geol., 88, 353-360.

Norton, D. A. (1989), Tree windthrow and forest soil turnover, Can. J. For Res., 19, 386-389.

Palmer, A. S. (1982), Kawakawa Tephra in Wairarapa, New Zealand, and its use for correlating Ohakea loess, N. Z. J. Geol. Geophys., 25, 305-315.

Pillans, B., M. McGlone, A. Palmer, D. Mildenhall, B. Alloway, G. Berger, T. C. Partridge, and M. A. J. Williams (1993), The Last Glacia Maximum in central and southern North Island, New Zealand: A paleoenvironmental reconstruction using the Kawakawa Tephra formation as a chronostratigraphic marker, Palaeogeogr. Palaeoclimatol Palaeoecol., 101, 283-304.

Press, W. H., S. A. Teukolsky, W. T. Vetterling, and B. P. Flannery (1992), Numerical Recipes in C: The Art of Scientific Computing, 994 pp., Cambridge Univ. Press, New York.

Riebe, C. S., J. W. Kirchner, D. E. Granger, and R. C. Finkel (2001), Strong tectonic and weak climatic control of long-term chemical weathering rates, Geology, 29, 511-514.

Roering, J. J., J. W. Kirchner, and W. E. Dietrich (1999), Evidence for nonlinear, diffusive sediment transport on hillslopes and implications for landscape morphology, Water Resour. Res., 35, 853-870.

Roering, J. J., J. W. Kirchner, and W. E. Dietrich (2001a), Hillslope evolution by nonlinear, slope-dependent transport: Steady state morphology and equilibrium adjustment timescales, J. Geophys. Res., 106(B8), $16,499-16,513$

Roering, J. J., J. W. Kirchner, L. S. Sklar, and W. E. Dietrich (2001b) Hillslope evolution by nonlinear creep and landsliding: An experimental study, Geology, 29, 143-146.
Roering, J., P. Almond, J. McKean, and P. Tonkin (2002), Soil transport driven by biological processes over millenial timescales, Geology, 30, $1115-1118$

Rosenbloom, N. A., and D. S. Schimel (1996), Predicting the interaction between long-term hillslope mass transport and vegetation dynamics (abstract), Eos Trans. AGU, 77(46), Fall Meet. Suppl., F253-F254.

Schaetzl, R. J. (1986), Complete soil profile inversion by tree uprooting, Phys. Geogr., 7(2), 181-189.

Schaetzl, R. J., S. F. Burns, T. W. Small, and D. L. Johnson (1990), Tree uprooting: Review of types and patterns of soil disturbance, Phys. Geogr. 11(3), 277-291.

Seidl, M. A., and W. E. Dietrich (1992), The problem of channel erosion into bedrock, Catena, 23, suppl., 101-124

Small, E. E., and R. S. Anderson (1998), Pleistocene relief production in Laramide mountain ranges, western United States, Geology, 26, 123126.

Small, E. E., R. S. Anderson, and G. S. Hancock (1999), Estimates of the rate of regolith production using ${ }^{10} \mathrm{Be}$ and ${ }^{26} \mathrm{Al}$ from an alpine hillslope, Geomorphology, 27, 131-150.

Small, T. W., R. J. Schaetzl, and J. M. Brixie (1990), Redistribution and mixing of soil gravels by tree uprooting, Prof. Geogr., 42, 445-457.

Snyder, N. P. K. X. Whipple, G. E. Tucker, and D. J. Merritts (2000), Landscape response to tectonic forcing: Digital elevation model analysis of stream profiles in the Mendocino triple junction region, northern California, Geol. Soc. Am. Bull., 112(8), 1250-1263.

Stock, J. D., and W. E. Dietrich (1999), Valley incision by debris flows: Field evidence and hypotheses linking flow frequency to morphology (abstract), Eos Trans. AGU, 80(46), Fall Meet. Suppl., F473.

Stonestrom, D. A., A. F. White, and K. C. Akstin (1998), Determining rates of chemical weathering in soils-Solute transport versus profile evolution, J. Hydrol., 209, 331-345.

Tonkin, P., and L. R. Basher (1990), Soil-stratigraphic techniques in the study of soil and landform evolution across the Southern Alps, New Zealand, Geomorphology, 3, 547-575.

Whipple, K. X. (2001), Fluvial landscape response time: How plausible is steady-state denudation?, Am. J. Sci., 301, 313-325.

Willett, S. D., and M. T. Brandon (2002), On steady states in mountain belts, Geology, 30, 175-178.

Worona, M., and C. Whitlock (1995), Late Quaternary vegetation and climate history near Little Lake, central Coast Range, Oregon, Geol. Soc. Am. Bull., 107, 867-876.

Yoo, K., R. Amundson, A. M. Heimsath, and W. E. Dietrich (2001), Soil organic carbon redistribution by geomorphic processes in an undisturbed zero order annual grassland watershed, California, Eos Trans. $A G U$, 82(47), Fall Meet. Suppl., Abstract B32A-0110.

P. Almond and P. Tonkin, Soil and Physical Sciences Group, Soil, Plant, and Ecological Sciences Division, P.O. Box 84, Lincoln University, Canterbury, New Zealand. (almondp@lincoln.ac.nz; tonkinp@lincoln. ac.nz)

J. McKean, Rocky Mountain Research Station, Forest Service, United States Department of Agriculture, 316 East Myrtle Street, Boise, ID 83702, USA. (jmckean@fs.fed.us)

J. J. Roering (corresponding author), Department of Geological Sciences, University of Oregon, Eugene, OR 97403-1272, USA. (jroering@darkwing. uoregon.edu) 